\title{
INFLATION, OUTPUT, AND MARKUP DYNAMICS WITH FORWARD-LOOKING WAGE AND PRICE SETTERS
}

\author{
Louis Phaneuf \\ Eric R. Sims \\ Jean Gardy Victor \\ Working Paper 21599 \\ http://www.nber.org/papers/w21599 \\ NATIONAL BUREAU OF ECONOMIC RESEARCH \\ 1050 Massachusetts Avenue \\ Cambridge, MA 02138 \\ September 2015
}

The views expressed herein are those of the authors and do not necessarily reflect the views of the National Bureau of Economic Research.

NBER working papers are circulated for discussion and comment purposes. They have not been peerreviewed or been subject to the review by the NBER Board of Directors that accompanies official NBER publications.

(C) 2015 by Louis Phaneuf, Eric R. Sims, and Jean Gardy Victor. All rights reserved. Short sections of text, not to exceed two paragraphs, may be quoted without explicit permission provided that full credit, including $(\mathcal{C}$ notice, is given to the source. 
Inflation, Output, and Markup Dynamics with Forward-Looking Wage and Price Setters

Louis Phaneuf, Eric R. Sims, and Jean Gardy Victor

NBER Working Paper No. 21599

September 2015

JEL No. E00,E1,E4

\begin{abstract}
$\underline{\text { ABSTRACT }}$
We formulate a medium-scale DSGE model that emphasizes a strong interplay between a roundabout production structure and a working capital channel that requires firms to borrow funds to finance the costs of all their variable inputs and not just the wage bill. Despite an absence of backward-looking price and wage indexation, our model is able to account for (i) a persistent and hump-shaped response of inflation to a monetary policy shock, (ii) a large and persistent response of output to a monetary policy shock, (iii) a mild "price puzzle," (iv) a procyclical price markup conditional on a monetary shock, (v) non-inertial responses of inflation to non-monetary shocks, and (vi) a negative unconditional autocorrelation of the first difference of inflation that is consistent with the data. A medium-scale model relying on backward indexation of wages and prices to past inflation fails along several of these dimensions.
\end{abstract}

Louis Phaneuf

Department of Economics

University of Quebec at Montreal

320 Ste Catherine east

DS-5975

Montreal

Canada H3C 3P8

phaneuf.louis@uqam.ca

Eric R. Sims

Department of Economics

University of Notre Dame

723 Flanner Hall

South Bend, IN 46556

and NBER

esims1@nd.edu
Jean Gardy Victor

Department of Economics

University of Quebec at Montreal

320, Ste-Catherine East

DS-5974

Montréal

CANADA

victor.jean_gardy@uqam.ca 


\section{Introduction}

In this paper we challenge the view that New Keynesian models with purely forward-looking wage and price setting cannot explain inertial inflation and output dynamics in response to changes in aggregate demand (Chari, Kehoe and McGrattan, 2000; Mankiw and Reis, 2002). We also call into question a well-received idea that New Keynesian models must rely on a countercyclical markup of price over marginal cost as the key transmission channel for demand shocks, something which does not seem consistent with the data (Nekarda and Ramey, 2013). While abstracting from ad hoc backward-looking wage and price setting mechanisms, we show that a medium-scale DSGE model emphasizing a roundabout production structure and a working capital channel allowing firms to cover the costs of all of their variable inputs, and not only the wage bill, can successfully address some of these apparent failures of purely forward-looking New Keynesian models. ${ }^{1}$

To formalize these ideas, we develop a medium-scale DSGE framework in the spirit of the model in Christiano, Eichenbaum, and Evans (2005) (hereafter CEE) (see also Smets and Wouters, 2007; Justiniano and Primiceri, 2008; Justiniano, Primiceri, Tambalotti, 2010, 2011). It shares some basic elements of this model like imperfectly competitive goods and labor markets, nominal wage and price rigidities in the form of Calvo (1983) contracts, and real frictions such as consumer habit formation, variable capital utilization, and investment adjustment costs. However, it departs from the CEE model along three important dimensions.

First, it does not rest on assumptions like the indexation of nominal wages and prices to the previous quarter's rate of inflation (CEE, 2005) or rule-of-thumb behavior of price setters (Galí and Gertler, 1999). The use of indexation has been criticized by a number of researchers. For instance, Woodford (2007) argues that "the model's implication that prices should continuously adjust to changes in prices elsewhere in the economy flies in the face of the survey evidence." Cogley and Sbordone (2008) mention that backward wage and price setting mechanisms "lack a convincing microeconomic foundation." Finally, Chari et al. (2009) criticize indexation because "this feature is inconsistent with microeconomic evidence on price setting." In spite of these criticisms, indexation has been routinely embedded in medium-scale models as a mechanism by which to generate more inflation inertia.

Second, our model assumes a roundabout production structure. Working from a state-dependent pricing model, Basu (1995) shows that the interaction between price stickiness and roundabout production can deliver a "multiplier for price stickiness" that enhances the degree of price inertia.

\footnotetext{
${ }^{1}$ One notable exception of a forward-looking New Keynesian model that can successfully explain inflation persistence is Cogley and Sbordone (2008), who incorporate a time-varying inflation trend in the New Keynesian Phillips Curve (NKPC). Our approach is different.
} 
Bergin and Feenstra (2000) and Dotsey and King (2006) incorporate roundabout production in a time-dependent price setting model, showing it helps to generate stronger output persistence in response to a monetary policy shock. Huang, Liu, and Phaneuf (2004) combine roundabout production with nominal wage and price rigidities in a DSGE framework and endogenously explain why real wages have changed from countercyclical during the interwar period to procyclical during the postwar period. In our model, we show that roundabout production is one of two key factors that a medium-scale macro model with purely forward-looking wage and price setting should include to successfully account for inflation and output dynamics and the actual behavior of the price markup.

Third, our model includes a working capital channel. Evidence in Barth and Ramey (2002) based on industry level data confirms the importance of a cost channel of monetary transmission. Chowdhury, Hoffmann, and Schabert (2006) provide further structural evidence on the relevance of a cost channel through estimation of marginal cost based Phillips curves accounting for direct interest rate effects. They find that changes in short-run nominal interest rates exert a substantial direct effect on inflation dynamics in most G7 countries.

We assume that working capital is required due to a delay between factor payments and sales receipts (Fuerst, 1992). In Christiano and Eichenbaum (1992), CEE (1997, 2005) and Ravenna and Walsh (2006) firms need to borrow funds from a financial intermediary at the start of a period to finance their wage bill. They then reimburse the loan at the end of the period at the nominal interest rate. We refer to this case as "Limited borrowing." But firms may not be constrained to finance only the wage bill with working capital. They may have access to "Extended borrowing" in the sense that the funds they borrow can serve to finance the costs of all of their variable inputs. ${ }^{2}$ As our paper shows, extended borrowing is the second of two main factors driving our new results.

We use this framework to address several questions. A first question is: what are the conditions, if any, that our model must satisfy to be able to generate a persistent and hump-shaped response of inflation to a monetary policy shock in the absence of backward-looking elements in price setting? A second and complementary question is: can the model deliver "large" contract multipliers for output in the terminology of Chari et al. (2000)?

Our baseline model predicts a weak negative response of inflation on impact of a negative shock to the nominal interest rate; the response will be very persistent and hump-shaped afterwards. Accompanying our findings regarding the shape of the inflation response, we also show that our model delivers highly serially correlated movements in inflation even at a lag of one year (Fuhrer

\footnotetext{
${ }^{2}$ Christiano, Trabandt, and Walentin (2011) combine roundabout production and working capital in a model that features sticky prices, but abstracts from several features like nominal wage rigidity, capital accummulation (and thus variable capital utilization and investment adjustment costs), and consumer habit formation. They use this model to examine conditions leading to (in)determinacy in monetary policy.
} 
and Moore, 1995; Nelson, 1998; Pivetta and Reis, 2007). The two main factors which explain these findings are the roundabout production structure and extended borrowing. Without these features, the peak response of inflation to a monetary shock is on impact and there is no hump-shape. Roundabout production induces strategic complementarity into price setting, and is thus isomorphic to prices being stickier. As such, it "flattens" the New Keynesian Phillips Curve (NKPC), making inflation less sensitive to changes in real marginal cost by a factor of proportionality reflecting the share of intermediate inputs into production. The inflation response to a policy shock is then smaller and more persistent. Extended borrowing contributes to make the response of inflation very hump-shaped. Because of working capital, the nominal interest rate has a direct effect on marginal cost, limiting the initial increase in marginal cost associated with an expansionary policy shock. Via the Phillips Curve, a smaller increase in marginal cost keeps inflation from initially rising by as much. Since the cut in interest rates is only temporary, as the interest rate begins to rise after impact due to the expansionary effects of the policy shock, marginal cost also begins to rise, which puts upward pressure on inflation and results in hump-shaped inflation dynamics.

Output responds significantly to a monetary policy shock and in a hump-shaped, inertial fashion. The response of output to a policy shock is significantly larger than in versions of the model without roundabout production and extended borrowing. We find that the half-life of output conditional on a monetary shock is fourteen quarters, or three and a half years. This is substantially larger than the output half-life in a model without extended borrowing and roundabout production, and is also higher than the half-life in a version of the model with backward indexation. Although wage and price setters are purely forward-looking, our model is not prone to the criticism raised by Chari et al. (2000) concerning the inability of general equilibrium models with nominal rigidities to deliver large contract multipliers for output conditional on monetary policy shocks.

Interestingly, our model is able to deliver a persistent and hump-shaped response of inflation, and a large and persistent response of output, without assuming counterfactually long waiting times between wage and price adjustments. In our baseline model, the median time waiting time between wage and price adjustments is 5.1 months, which is broadly consistent with the evidence in micro data for price setting in Bils and Klenow (2004). ${ }^{3}$ The assumed median duration between wage changes is similar to the macro estimates reported in CEE (2005) and Altig et al. (2011), and is actually a bit conservative with respect to the micro evidence reported in Barattieri, Basu, and Gottschalk (2014).

\footnotetext{
${ }^{3}$ Cogley and Sbordone (2008) focus on evidence about the median waiting time of price adjustments which is 5.5 months in Bils and Klenow (2004) once sales price changes are removed. Nakamura and Steinsson (2008) find a longer median duration of about eight months after excluding sales and product substitutions.
} 
A third question which is the object of our attention is: is the model capable of generating a "price puzzle," in which inflation falls in the period of an expansionary monetary shock? Empirical evidence, dating back to at least Sims (1992), often finds that inflation initially falls at the onset of an expansionary monetary policy shock, before rising in a hump-shaped fashion. ${ }^{4}$ Barth and Ramey (2002) provide VAR evidence that a cost channel can be a significant factor giving rise to a price puzzle. But the question remains open as to whether a New Keynesian model with purely forward-looking wage and price setters could generate a price puzzle. ${ }^{5}$

We show that our baseline model delivers a mild price puzzle in the sense that inflation does in fact initially fall in the period of an expansionary policy shock. This drop in inflation is small and lasts only one period. For our baseline parameterization, the coexistence of extended borrowing and roundabout production is necessary to generate a price puzzle. Two other factors in the model can contribute to making the price puzzle larger and more persistent. One is to increase the average waiting time between wage adjustments to make it consistent with the microeconomic evidence of Barattieri, Basu, and Gottschalk (2014). These authors report that the quarterly probability of a wage change lies between 21 and 27 percent. As it happens, Justiniano et al. $(2010,2011)$ report estimates in this range using multi-shock DSGE models. The other factor we identify is a smaller cost of capital utilization in line with the parameterization in CEE (2005). ${ }^{6}$ Stickier wages mechanically limit the initial rise in marginal cost after an expansionary policy shock, which helps to keep the response of inflation down. More variable capital utilization keeps the rental rate on capital from rising as much, which also works to keep marginal cost, and hence inflation, from rising initially.

The fourth main question motivating our work is the following: can our model deliver a procyclical price markup conditional on a monetary policy shock? This question follows from evidence

\footnotetext{
${ }^{4}$ We do not want to take a firm stand as to whether the price puzzle is a robust empirical fact or not. Some evidence supports the existence of a price puzzle (CEE, 1999, 2005), while some other evidence can be used to question the existence of a price puzzle (Bernanke and Mihov, 1998; Normandin and Phaneuf, 2004; Romer and Romer, 2004). Carlstrom, Fuerst, and Paustian (2009) show that timing assumptions commonly used in structural VAR identification of monetary policy shocks may produce a price puzzle and an inertial response of inflation if these timing assumptions are inconsistent with the underlying economic model.

${ }^{5}$ The model in CEE (2005) is capable of generating a mild price puzzle without full backward-indexation, but there are some differences relative to our setup. One important difference, which is touched on below, is that their model is parameterized in such a way that the cost of capital utilization is virtually linear, which has the effect of making the rental rate on capital roughly constant, which limits the increase in marginal cost after a policy shock and therefore makes it more likely for a price puzzle to emerge. Another is that their model embeds timing assumptions on the delayed effects of policy shocks which ours does not. A third difference is that they model monetary policy via an exogenous money growth rule, whereas we model policy via a Taylor rule which allows for endogenous feedback from inflation and economic activity to interest rates. Though they also consider robustness to a Taylor rule, they do not present results for a Taylor rule without full backward indexation.

${ }^{6}$ As described later in the text, their parameterization implies that the cost of capital utilization is nearly linear. Our parameterization is more conservative than this and is more in-line with estimates from several papers which structurally estimate this parameter in a model with multiple shocks.
} 
recently reported by Nekarda and Ramey (2013), who argue that the price markup is either mildly procyclical or acyclical unconditionally. Furthermore, their evidence suggests that the price markup responds positively to a negative shock to the nominal interest rate. A procylical price markup runs counter to the conventional wisdom from textbook New Keynesian models that a countercyclical markup is the key transmission mechanism of aggregate demand shocks (e.g. Woodford, 2003, 2011).

Our model generates a procyclical price markup conditioning on a monetary shock. The correlation between first-differences of the price markup and output is about 0.4 , which is very close to the unconditional correlation reported in Nekarda and Ramey (2013). Measured in log-levels or HP-filtered log-levels, we also find a procyclical price markup conditional on a policy shock, although the correlation is not as high as in first differences. Abstracting from roundabout production or extended borrowing results in a countercyclical price markup. Without extended borrowing, the price markup is very procyclical, whether roundabout production is in the model or not. With limited borrowing, in which only the wage bill must be financed, the markup is also countercyclical. Backward price and wage indexation, though capable of generating hump-shaped inflation dynamics, cannot generate a procyclical markup without other features also in the model. Our baseline model generates a persistent and large response of output in spite of the procyclicality of the markup, which challenges the widely-held view that a counteryclical markup is the key transmission mechanism for demand shocks in New Keynesian models.

Our last substantive finding concerns the unconditional first-order autocorrelation of the first difference of inflation. This correlation is -0.29 in US data for the years 1960-2015. We augment the model to include a productivity shock and a preference shock, the latter meant as a stand-in for an aggregate demand disturbance other than a monetary policy shock. Our model predicts non-inertial responses of inflation to non-monetary shocks. We argue this is consistent with evidence reported elsewhere in the VAR literature. The first difference of inflation is positively autocorrelated conditional on the monetary policy shock and negatively autocorrelated conditional on the productivity and preference shocks. Unconditionally, our baseline parameterization of these shock processes results in an autocorrelation of the first difference of inflation of -0.1 , which is qualitatively in-line with what one observes in the data. For point of comparison, we show that a model with full backward indexation of prices and wages results in hump-shaped inflation dynamics conditional on all shocks, and therefore generates a highly positive autocorrelation of the first difference of inflation unconditionally, which is strongly at odds with the data.

The remainder of the paper is organized as follows. Section 2 lays out our medium-scale DSGE model and discusses our calibration. Section 3 presents results for inflation and output dynamics, 
the price puzzle, the cyclicality of the price markup, and the autocorrelation of the first difference of inflation. Section 4 contains concluding remarks.

\section{A Medium-Scale DSGE Model with Roundabout Production and Extended Borrowing}

We propose a medium-scale DSGE model in the spirit of CEE (2005). It includes nominal rigidities in the form of Calvo wage and price contracts, habit formation in consumption, investment adjustment costs, variable capital utilization and a Taylor rule. We augment the model to include a roundabout production structure and an extended working capital or cost channel. The subsections below lay out the decision problems of the relevant model actors. The full set of conditions characterizing the equilibrium are shown in the Appendix.

\subsection{Good and Labor Composites}

There is a continuum of firms, indexed by $j \in(0,1)$, producing differentiated goods with the use of a composite labor input. The composite labor input is aggregated from differentiated labor skills supplied by a continuum of households, indexed by $h \in(0,1)$. Differentiated goods are bundled into a gross output good, $X_{t}$. Some of this gross output good can be used as a factor of production by firms. Net output is then measured as gross output less intermediate inputs. Households can either consume or invest the final net output good. The composite gross output and labor input are:

$$
\begin{aligned}
X_{t} & =\left(\int_{0}^{1} X_{t}(j)^{\frac{\theta-1}{\theta}} d j\right)^{\frac{\theta}{\theta-1}} \\
L_{t} & =\left(\int_{0}^{1} L_{t}(h)^{\frac{\sigma-1}{\sigma}} d h\right)^{\frac{\sigma}{\sigma-1}}
\end{aligned}
$$

The parameters $\theta>1$ and $\sigma>1$ denote the elasticities of substitution between goods and labor, respectively. The demand schedules for goods of type $j$ and labor of type $i$ respectively are:

$$
\begin{gathered}
X_{t}(j)=\left(\frac{P_{t}(j)}{P_{t}}\right)^{-\theta} X_{t} \quad \forall j, \\
L_{t}(h)=\left(\frac{W_{t}(h)}{W_{t}}\right)^{-\sigma} L_{t} \quad \forall h .
\end{gathered}
$$

The aggregate price and wage indexes are:

$$
P_{t}^{1-\theta}=\int_{0}^{1} P_{t}(j)^{1-\theta} d j
$$




$$
W_{t}^{1-\sigma}=\int_{0}^{1} W_{t}(h)^{1-\sigma} d h
$$

\subsection{Households}

There is a continuum of households, indexed by $h \in(0,1)$, who are monopoly suppliers of labor. They face a downward-sloping demand curve for their particular type of labor given in (4). Following Calvo (1983), each period, there is a fixed probability, $\left(1-\xi_{w}\right)$, that households can adjust their nominal wage, with $0 \leq \xi_{w}<1$. Non-updated wages may be indexed to lagged inflation via the parameter $\zeta_{w} \in[0,1]$. As in Erceg, Henderson, and Levin (2000), we assume that utility is separable in consumption and labor. State-contingent securities insure households against idiosyncratic wage risk arising from staggered wage setting. With this setup, households are identical along all dimensions other than labor supply and nominal wages. We therefore suppress dependence on $h$ except for choice variables related to the labor market.

The problem of a particular household is to optimize the present discounted value of flow utility subject to a flow budget constraint, (8), a law of motion for physical capital, (9), the demand curve for labor, (10), and a constraint describing the Calvo wage setting process, (11):

$$
\begin{gathered}
\max _{C_{t}, L_{t}(h), W_{t}(h), K_{t+1}, B_{t+1}, I_{t}, Z_{t}} \quad E_{0} \sum_{t=0}^{\infty} \beta^{t}\left(\ln \left(C_{t}-b C_{t-1}\right)-\eta \frac{L_{t}(h)^{1+\chi}}{1+\chi}\right) \\
\text { s.t. } \\
P_{t}\left(C_{t}+I_{t}+a\left(Z_{t}\right) K_{t}\right)+\frac{B_{t+1}}{1+i_{t}} \leq W_{t}(h) L_{t}(h)+R_{t}^{k} Z_{t} K_{t}+\Pi_{t}+T_{t} B_{t}
\end{gathered}
$$

$P_{t}$ is the nominal price of goods, $C_{t}$ is consumption, $I_{t}$ is investment, $K_{t}$ is the physical capital stock, and $Z_{t}$ is the level of capital utilization. $W_{t}(h)$ is the nominal wage paid to labor of type $h$, and $R_{t}^{k}$ is a common rental price on capital services (the product of utilization and physical capital). $\Pi_{t}$ represents distributed dividends from firms and a financial intermediate, which households take as given. $T_{t}$ denotes lump sum transfers. $B_{t}$ is the stock of nominal bonds with which the household enters the period. The nominal interest on these bonds is $i_{t} . a\left(Z_{t}\right)$ is a resource cost of utilization, 
satisfying $a(1)=0, a^{\prime}(1)=0$, and $a^{\prime \prime}(1)>0$. This resource cost is measured in units of physical capital. $S\left(\frac{I_{t}}{I_{t-1}}\right)$ is an investment adjustment cost, satisfying $S(1)=0, S^{\prime}(1)=0$, and $S^{\prime \prime}(1)>0$. $0<\beta<1$ is a discount factor, $0<\delta<1$ is a depreciation rate, and $0 \leq b<1$ is a parameter for internal habit formation. $\chi$ is the inverse Frisch labor supply elasticity and $\eta$ is a scaling parameter on the disutility from labor. It is straightforward to show that all households given the opportunity to change their wage will adjust to a common reset wage, $W_{t}^{*}$.

\section{$2.3 \quad$ Firms}

The production function for a typical producer $j$ is:

$$
X_{t}(j)=\max \left\{\Gamma_{t}(j)^{\phi}\left(\widehat{K}_{t}(j)^{\alpha} L_{t}(j)^{1-\alpha}\right)^{1-\phi}-F, 0\right\}
$$

The parameter $F$ is a fixed cost, and production is required to be non-negative. We choose the value of $F$ such that profits are zero in steady state, which allows us to ignore entry and exit. $\Gamma_{t}(j)$ is the amount of intermediate input, and $\phi \in(0,1)$ is the intermediate input share. Intermediate

inputs come from aggregate gross output, $X_{t} . \widehat{K}_{t}(j)$ is capital services (the product of physical capital and utilization), while $L_{t}(j)$ is labor input.

A firm gets to choose its price, $P_{t}(j)$, as well as quantities of the intermediate input, capital services, and labor input. It is subject to Calvo pricing, where each period there is a $\left(1-\xi_{p}\right)$ probability that a firm can re-optimize its price, with $0 \leq \xi_{p}<1$. Non-updated prices may be indexed to lagged inflation at $\zeta_{p} \in[0,1]$. In other words, a firm's price satisfies:

$$
P_{t}(j)= \begin{cases}P_{t}^{*}(j) & w / \text { prob } 1-\xi_{p} \\ \left(1+\pi_{t-1}\right)^{\zeta_{p}} P_{t-1}(j) & \text { otherwise }\end{cases}
$$

An updating firm will choose its price to maximize the present discounted value of flow profit, where discounting is by the stochastic discount factor of households as well as the probability that a price chosen today will still be in effect in the future. It is straightforward to show that all firms given the ability to change their price will adjust to a common reset price, $P_{t}^{*}$.

Regardless of whether a firm can re-optimize its price, it will always choose inputs so as to minimize cost, subject to the constraint of meeting demand at its price. A key assumption is that firms must finance some or all of their variable inputs through intra-period loans from a financial intermediary. The financial intermediary returns the interest earned on these loans to the household 
lump sum. The cost-minimization problem of a typical firm is:

$$
\min _{\Gamma_{t}, \widehat{K}_{t}, L_{t}}\left(1-\psi_{\Gamma}+\psi_{\Gamma}\left(1+i_{t}\right)\right) P_{t} \Gamma_{t}+\left(1-\psi_{K}+\psi_{K}\left(1+i_{t}\right)\right) R_{t}^{k} \widehat{K}_{t}+\left(1-\psi_{L}+\psi_{L}\left(1+i_{t}\right)\right) W_{t} L_{t}
$$

$$
\Gamma_{t}^{\phi}\left(\widehat{K}_{t}^{\alpha} L_{t}^{1-\alpha}\right)^{1-\phi}-F \geq\left(\frac{P_{t}(j)}{P_{t}}\right)^{-\theta} X_{t}
$$

Here $\psi_{l}, l=\Gamma, K, L$, is the fraction of payments to a factor that must be financed at the gross nominal interest rate, $1+i_{t}$. With $\psi_{l}=0$ for all $l$, firms do not have to borrow to pay any of their factors. Setting $\psi_{\Gamma}=\psi_{K}=0$ and $\psi_{L}=1$ means that firms make use of working capital to finance the entirety of their wage bill as in CEE $(1997 ; 2005)$ and Ravenna and Walsh (2006). We refer to this case as limited borrowing (LB). Assuming $\psi_{l}=1$ for all $l$ means that all factor payments are financed through working capital, so that the factor prices relevant for firms are the product of the gross nominal interest rate and the factor price. We refer to this case as extended borrowing (EB). To economize on notation, we define $\Psi_{l}=\left(1-\psi_{l}+\psi_{l}\left(1+i_{t}\right)\right)$ for $l=\Gamma, K, L$.

Applying some algebraic manipulations to the first order conditions for the cost-minimization problem yields and expression for real marginal cost, $v_{t} \equiv \frac{V_{t}}{P_{t}}$, which is common across all firms:

$$
v_{t}=\Psi_{\Gamma} \frac{1}{\phi}\left(\frac{\phi}{1-\phi} \frac{1}{\alpha} \frac{\Psi_{K} r_{t}^{k}}{\Psi_{\Gamma}}\right)^{1-\phi}\left(\frac{\alpha}{1-\alpha} \frac{\Psi_{L} w_{t}}{\Psi_{K} r_{t}^{k}}\right)^{(1-\alpha)(1-\phi)}
$$

The variables $r_{t}^{k}$ and $w_{t}$ are the real rental rate on capital services and the real wage for labor, respectively. This general expression encompasses several special cases. If the model excludes roundabout production $(\phi=0)$ and financial intermediation $\left(\Psi_{l}=1\right.$ for all $\left.l\right)$, then real marginal cost reduces to its simplest expression:

$$
v_{t}=\left(\frac{1}{1-\alpha}\right)^{1-\alpha}\left(\frac{1}{\alpha}\right)^{\alpha}\left(r_{t}^{k}\right)^{\alpha}\left(w_{t}\right)^{1-\alpha}
$$

The case of roundabout production without working capital yields:

$$
v_{t}=\frac{1}{\phi}\left(\frac{\phi}{1-\phi}\right)^{1-\phi}\left(\frac{1}{\alpha}\right)^{\phi}\left(\frac{\alpha}{1-\alpha}\right)^{(1-\alpha)(1-\phi)}\left(r_{t}^{k}\right)^{\alpha(1-\phi)}\left(w_{t}\right)^{(1-\alpha)(1-\phi)}
$$

The presence of roundabout production reduces the sensitivity of real marginal cost to variations in the real rental on capital services and the real wage rate by a factor of $1-\phi$. For the case of 
limited borrowing (LB), in which only the wage bill must be financed via working capital, and no roundabout production, the expression for marginal cost is:

$$
v_{t}=\left(1+i_{t}\right)^{1-\alpha}\left(\frac{1}{1-\alpha}\right)^{1-\alpha}\left(\frac{1}{\alpha}\right)^{\alpha}\left(r_{t}^{k}\right)^{\alpha}\left(w_{t}\right)^{1-\alpha}
$$

In this case the nominal interest rate exerts a direct influence on real marginal cost. Combining extended borrowing and roundabout production yields:

$$
v_{t}=\left(1+i_{t}\right) \frac{1}{\phi}\left(\frac{\phi}{1-\phi} \frac{1}{\alpha} r_{t}^{k}\right)^{1-\phi}\left(\frac{\alpha}{1-\alpha} \frac{w_{t}}{r_{t}^{k}}\right)^{(1-\alpha)(1-\phi)}
$$

Like the case with LB, here the nominal interest rate exerts a direct influence on real marginal cost. Relative to (19), the effect of the nominal rate on marginal cost is stronger with EB, in which all factors must be fully financed via working capital. Like the expression for real marginal cost with only roundabout production, the sensitivity of real marginal cost to fluctuations in the real rental rate and real wage is smaller by a factor of $1-\phi$.

\subsection{Monetary Policy}

Monetary policy follows a Taylor rule:

$$
\frac{1+i_{t}}{1+i}=\left(\frac{1+i_{t-1}}{1+i}\right)^{\rho_{i}}\left[\left(\frac{\pi_{t}}{\pi}\right)^{\alpha_{\pi}}\left(\frac{Y_{t}}{Y_{t-1}}\right)^{\alpha_{y}}\right]^{1-\rho_{i}} \varepsilon_{t}^{i}
$$

The nominal interest rate responds to deviations of inflation from an exogenous steady-state target, $\pi$, and to output growth, $\frac{Y_{t}}{Y_{t-1}} \cdot{ }^{7}$ The exogenous variable $\varepsilon_{t}^{i}$ is an i.i.d. normal process, with a zero mean and a finite known variance $s_{i}$. The parameter $\rho_{i}$ governs the smoothing-effect on nominal interest rates while $\alpha_{\pi}$ and $\alpha_{y}$ are control parameters. We restrict attention to parameter configurations resulting in a determinate rational expectations equilibrium.

\subsection{Aggregation}

Given properties of Calvo (1983) price and wage setting, aggregate inflation and the real wage evolve according to:

$$
\begin{gathered}
1=\xi_{p} \pi_{t}^{\theta-1} \pi_{t-1}^{\zeta_{p}(1-\theta)}+\left(1-\xi_{p}\right)\left(p_{t}^{*}\right)^{1-\theta} \\
w_{t}^{1-\sigma}=\xi_{w}\left(\frac{w_{t-1} \pi_{t-1}^{\zeta_{w}}}{\pi_{t}}\right)^{1-\sigma}+\left(1-\xi_{w}\right)\left(w_{t}^{*}\right)^{1-\sigma}
\end{gathered}
$$

\footnotetext{
${ }^{7}$ We abstract from trend growth in output.
} 
The notation here is that $\pi_{t} \equiv \frac{P_{t}}{P_{t-1}}$ is aggregate gross inflation, $p_{t}^{*} \equiv \frac{P_{t}^{*}}{P_{t}}$ is the relative reset price, $w_{t} \equiv \frac{W_{t}}{P_{t}}$ is the real wage, and $w_{t}^{*} \equiv \frac{W_{t}^{*}}{P_{t}}$ is the real reset wage. Market-clearing for capital services, labor, and intermediate inputs requires that $\int_{0}^{1} \widehat{K}_{t}(j) d j=\widehat{K}_{t}, \int_{0}^{1} L_{t}(j) d j=L_{t}$, and $\int_{0}^{1} \Gamma_{t}(j) d j=\Gamma_{t}$. This means that aggregate gross output can be written:

$$
s_{t} X_{t}=\Gamma_{t}^{\phi}\left(\widehat{K}_{t}^{\alpha} L_{t}^{1-\alpha}\right)^{1-\phi}-F
$$

where $s_{t}$ is a price dispersion variable that can be written recursively:

$$
s_{t}=\left(1-\xi_{p}\right) p_{t}^{*-\theta}+\xi_{p} \pi_{t-1}^{-\zeta_{p} \theta} \pi_{t}^{\theta} s_{t-1}
$$

Using the market-clearing conditions, the aggregate factor demands can be written:

$$
\begin{gathered}
\Gamma_{t}=\phi v_{t} \Psi_{\Gamma}^{-1}\left(X_{t}+F\right) \\
\widehat{K}_{t}=\alpha(1-\phi) \frac{v_{t}}{\Psi_{K} r_{t}^{k}}\left(X_{t}+F\right) \\
L_{t}=(1-\alpha)(1-\phi) \frac{v_{t}}{\Psi_{L} w_{t}}\left(X_{t}+F\right)
\end{gathered}
$$

Aggregate net output, $Y_{t}$, is gross output minus intermediate input:

$$
Y_{t}=X_{t}-\Gamma_{t}
$$

Integrating over household budget constraints yields the aggregate resource constraint:

$$
Y_{t}=C_{t}+I_{t}+a\left(Z_{t}\right) K_{t}
$$

\subsection{Functional Forms}

The resource cost of utilization and the investment adjustment cost function have the following functional forms:

$$
\begin{gathered}
a\left(Z_{t}\right)=\gamma_{1}\left(Z_{t}-1\right)+\frac{\gamma_{2}}{2}\left(Z_{t}-1\right)^{2} \\
S\left(\frac{I_{t}}{I_{t-1}}\right)=\frac{\kappa}{2}\left(\frac{I_{t}}{I_{t-1}}-1\right)^{2}
\end{gathered}
$$


where $\gamma_{2}>0$ is a free parameter; as $\gamma_{2} \rightarrow \infty$ utilization becomes fixed at unity. $\gamma_{1}$ must be restricted so that the optimality conditions are consistent with the normalization of steady state utilization of $1 . \kappa \geq 0$ is a free parameter. The functional form for the investment adjustment cost is standard in the literature (e.g. see Christiano et al., 2005).

\subsection{Calibration}

We use the calibration summarized in Table 1 . Some parameter values, like $\beta, b, \eta, \chi$ and $\delta$ are standard in the literature. Others require some explanations.

The parameter governing the size of investment adjustment costs $\kappa$ is 5 , which is somewhat lower than the estimate in Altig et al. (2011) but higher than the estimate in CEE (2005). The parameter on the squared term in the utilization adjustment cost is set to $\gamma_{2}=0.05$. This is broadly consistent with the evidence in Basu and Kimball (1997) and Dotsey and King (2006)), and is middle range between Justiniano, Primiceri, and Tambalotti (2010, 2011), who estimate this parameter to be about 0.15 , and CEE (2005), who fix this parameter at $0.00035 .{ }^{8}$ Later, we assess the sensitivity of getting a price puzzle when varying this parameter. The parameter $\theta$ is the elasticity of substitution between differentiated goods and is set at 6 . This implies a steady-state price markup of 20 percent, which is consistent with Rotemberg and Woodford (1997). The steadystate price markup is used in computing $\phi$ as we discuss below. The parameter $\sigma$ is the elasticity between differentiated labor skills and is also set at 6 (e.g., see Huang and Liu, 2002; Griffin, 1992).

The Calvo probabilities for wage and price non-reoptimization both initially take a value of 0.66. Bils and Klenow (2004) report that the median duration of prices is 5.5 months after removing sales price changes. In contrast, Nakamura and Steinsson (2008) find a longer median duration of about eight months after excluding sales and product substitutions. For a purely forward-looking Calvo model with no backward indexation, Cogley and Sbordone (2008) approximate the median waiting time of a price change by $-\ln (2) / \ln \left(\xi_{p}\right)$. Setting $\xi_{p}=0.66$ therefore implies a median duration of prices of 5.1 months, which is broadly consistent with the evidence reported in Bils and Klenow (2004), but somewhat shorter than the evidence in Nakamura and Steinsson (2008).

We set $\xi_{w}=0.66$, which implies an average waiting time between wage adjustments of 3 quarters. This is somewhat higher than the macro estimate of 0.64 reported in CEE (2005), but somewhat lower than the estimate of 0.71 in Altig et al. (2011). In some sensitivity analysis, we also look at the impact of a higher average duration of wage contracts. For this, we consider the evidence in Barattieri, Basu, and Gottschalk (2014), who analyze micro-data for the U.S. economy.

\footnotetext{
${ }^{8} \mathrm{CEE}$ set $\frac{\gamma_{2}}{\gamma_{1}}=0.01$; given the parameterization of $\gamma_{1}$ to be consistent with steady state utilization of unity, this implies $\gamma_{2}=0.00035$.
} 
They find that the average quarterly probability of a wage change lies between 0.211 and 0.266 , which would imply a value of $\xi_{w}$ in the range of $0.75-0.80$. Justiniano et al. $(2010,2011)$ also report higher estimates of $\xi_{w}$ in this range in Bayesian estimation of a model similar to ours augmented with several more shocks, but without roundabout production or a working capital channel.

The parameter $\phi$ measures the share of payments to intermediate inputs in total production. Nakamura and Steinsson (2010) summarize information from the 2002 U.S. Input-Output Table published by the Bureau of Economic Analysis. They document that the weighted average revenue share of intermediate inputs in the U.S. private sector using Consumer Price Index (CPI) expenditure weights was roughly 52 percent in 2002 . The cost share of intermediate inputs must equal the revenue share times the markup. Since our calibration of $\theta$ implies a steady state price markup of 1.2, this then implies $\phi=0.624$. This is lower than $\phi=0.7$ in Nakamura and Steinsson because they assume a lower value of $\theta$, implying a steady-state price markup of $1.33 .{ }^{9}$

The parameters of the Taylor rule include the smoothing parameter set at 0.8 , the coefficient on inflation at 1.5, and the coefficient on output growth at 0.2 . The standard deviation of the monetary policy shock $\sigma_{r}$ is set at 0.002 , which is consistent with the estimates reported in Justiniano et al. $(2010,2011)$. We assume that there is zero trend inflation, $\pi=0$. As a baseline we also assume that there is no backward indexation of prices or wages to lagged inflation, i.e. $\zeta_{p}=\zeta_{w}=0$. Finally, we take our baseline model to be the one with full extended borrowing, so that $\psi_{\Gamma}=\psi_{K}=\psi_{L}=1$.

\section{Results}

In this section we present results from the model. We take our "Base Model" to be the specification in which there is extended borrowing (EB), in which all three factors of production must be fully financed through working capital. We focus on impulse responses and second moments, and examine the roles that different model features play in generating the results. Subsection 3.1 focuses on the dynamic responses of output and inflation to a monetary policy shock. In Subsection 3.2 we examine the extent to which our model can generate a "Price Puzzle" and which model features play a role in that. Subsection 3.3 focuses on the cyclicality of the price markup conditional on monetary policy shocks. Subsection 3.4 examines the implications of our model for the unconditional autocorrelation of the first difference of inflation in relation to models with backward indexation.

\footnotetext{
${ }^{9}$ Note that Basu (1995) and Bergin and Feenstra (2000) argue for values of $\phi$ between 0.8 and 0.9. Huang, Liu, and Phaneuf (2004) favor a value of 0.7. Rotemberg and Woodford (1995), Chari, Kehoe, and McGrattan (1996), and Woodford (2003, Ch. 3) use values closer to 0.5. Thus, assuming $\phi=0.624$ seems to strike a middle ground.
} 


\subsection{Inflation and Output Dynamics}

Figure 1 plots the model impulse responses of output, inflation, and the price level to a one standard deviation expansionary monetary policy shock (i.e. a negative shock to the Taylor rule). The solid lines show the responses in the baseline model. For point of comparison, we also present impulse responses under two alternative specifications. The dashed lines show responses in which there is no extended borrowing (nor limited borrowing, so that none of the factors of production must be financed through working capital, i.e. $\psi_{\Gamma}=\psi K=\psi_{L}=0$ ) and no roundabout production (i.e $\phi=0)$. One can think of this specification as the "standard" medium scale New Keynesian DSGE model. The dotted lines show responses when there is no extended borrowing and no roundabout production, but in which prices and wages are fully indexed to lagged inflation (i.e. $\zeta_{p}=\zeta_{w}=1$ ).

In our baseline model output rises by about 0.2 percent on impact of the monetary policy shock. This jump is roughly half the magnitude of the peak output response, which is 0.4 percent and occurs about four quarters subsequent to the shock. The output response is quite persistent, and is still positive more than five years after the shock. The impact response of inflation is slightly negative. In other words, the model generates a mild "price puzzle" on impact, a point to which we return in more depth in Subsection 3.2. The inflation response turns positive in the next period and reaches its peak response after about four quarters. Like the output response, the inflation impulse response to the policy shock is quite persistent. Consistent with the behavior of inflation, the price level jumps down on impact but then slowly and persistently rises.

The dashed lines show impulse responses in the "standard" medium scale New Keynesian model in which there is no working capital required for any factors and there is no roundabout production. Relative to our baseline model, the impulse response of output is smaller on impact and at all horizons. Though it follows a hump-shaped pattern, the peak output responses occurs sooner and is smaller relative to the impact effect when compared to the baseline model. The response of inflation is very different when there is no working capital channel and no roundabout production. The peak response of inflation is on impact, with inflation jumping up substantially, and there is no hump-shaped pattern. The response of inflation is also not very persistent, with inflation back close to its pre-shock value after about two years. The price level rises and grows quickly.

The dotted lines take the "standard" New Keynesian model and modify it so that both prices and wages are fully indexed to one period lagged inflation (i.e. $\zeta_{p}=\zeta_{w}=1$ ). This kind of specification has been advanced in the literature as a way to generate more inertia in the response of inflation to a policy shock. This specification does result in a hump-shaped response of inflation, but the impact effect on inflation is still positive, so that the model is incapable of delivering a price 
puzzle. The inflation response also reverts to zero from its peak more quickly than in the baseline model which does not feature any indexation. The inclusion of backward indexation makes the output response to the policy shock smaller and less persistent.

Table 2 presents some statistics summarizing the dynamics of inflation and output in the impulse response functions. We calculate the half-life of output by finding the number of quarters it takes for the response of output to equal one-half its impact response (rounded to the nearest integer). In the baseline model the half-life of output is 14 quarters, or three and a half years. Even though price and wage setting is purely forward-looking in the model, it is not prone to the criticism of Chari, Kehoe, and McGrattan (2000) that nominal rigidities are not sufficient to generate a large contract multiplier for output in a general equilibrium framework with intertemporal links. In the model with no working capital and no roundabout production, the half-life of output is still substantial but half of a year shorter than in the baseline model at 12 quarters. The half-life of output is substantially lower in the model with full backward indexation of prices and wages, with a half-life of only one and a half years.

Table 2 also shows autocorrelation coefficients for inflation at different lag lengths. In the baseline model the first order autocorrelation of inflation is 0.92 . Inflation is highly persistent, with an autocorrelation coefficient at a one year lag of more than 0.5. The autocorrelation coefficients of inflation are higher (by 0.1 or more) at all lags in the Base Model relative to the version of the model with no working capital and no roundabout production. The model without working capital and roundabout production, but augmented with full backward indexation, produces a first order autocorrelation of inflation that is slightly higher than our baseline model (0.95 vs 0.92), but the autocorrelation at lags higher than 4 is higher in the baseline model than in the backward indexation model (0.53 vs 0.49 at a four quarter lag and 0.40 versus 0.32 at a five quarter lag).

The reasons why a model with backward indexation can produce a hump-shaped response of inflation to a monetary policy shock are well understood. But how is it that our model, which features no price or wage indexation, can also generate hump-shaped inflation dynamics? The two key model ingredients giving rise to this pattern are roundabout production and a working capital channel. Both of these channels can be seen in equation (20), which is the expression for real marginal cost in our model. Because working capital results in the nominal interest rate having a direct effect on marginal cost, it works to limit the increase in marginal cost associated with an expansionary policy shock. Via the traditional Phillips Curve, a smaller increase (or a decrease) in marginal cost keeps inflation from initially rising by as much. Because the cut in interest rates is only temporary, as the interest rate starts to rise after impact, marginal cost begins to rise, which puts upward pressure on inflation and can result in hump-shaped inflation dynamics. Roundabout 
production works through a similar channel. Positive values of $\phi$ limit the sensitivity of marginal cost to fluctuations in factor prices, and therefore allow output to expand by more without marginal cost (and hence inflation) rising by much.

To further elucidate these mechanisms, Figure 2 plots impulse responses of output and inflation to a policy shock for four different cases. The solid lines show the responses in our Base Model. The dashed lines present responses when roundabout production is turned off, which amounts to setting $\phi=0$. The dotted line shows responses with roundabout production but where there is no working capital channel, so that $\psi_{L}=\psi_{\Gamma}=\psi_{K}=0$. The dashed line with + markers shows responses when there is limited borrowing (so $\psi_{L}=1$, but $\psi_{\Gamma}=\psi_{K}=0$ ) with roundabout production.

We focus first on the response of inflation to a policy shock. From the Figure one observes that some degree of working capital (either LB or EB) is necessary to generate a hump-shaped inflation response - when there is no working capital at all, the impulse response of inflation is largest on impact, and exhibits no hump-shape. There is a bigger hump-shape in the inflation response when there is $\mathrm{EB}$ (so all factors must be financed via working capital) than when there is LB (so that labor is the only factor which must be financed). This is natural; when all factors must be financed, the effect of the interest rate on marginal cost is stronger than when just one factor must be financed. This effect can clearly be seen when comparing the expression for marginal cost in our baseline case, (20), to the case where working capital only applies to labor, (19). In the impulse responses roundabout production has the effect of limiting the inflation response on impact. When comparing the impulse response in Figure 2 when there is no EB to the response in Figure 1 where there is neither EB nor RP, one sees that the inflation response is significantly smaller on impact with RP than without. When there is no RP but all factors must be financed via working capital, the response of inflation is hump-shaped, but is positive on impact and the peak response occurs roughly three quarters subsequent to the shock. When EB is combined with RP, the impact response of inflation turns negative, and the peak response of inflation occurs about five quarters after the shock. In other words, while a working capital channel can generate a humpshaped inflation response, it is the interaction between working capital and roundabout production that can deliver a negative impact response of inflation. Roundabout production also accentuates the persistence in the inflation response induced by working capital.

We next turn attention to the output response. It is evident that the output response is largest and most persistent in our baseline model. In other words, working capital and roundabout production both serve as amplification mechanisms for a monetary policy shock. Both of these features limit the extent to which marginal cost rises after a policy shock, which therefore induces firms to hire more factors and therefore expand production more. 


\subsection{The Price Puzzle}

Our model is capable of generating a "price puzzle" in the sense that an expansionary monetary policy shock is initially associated with a decline in inflation, rather than an increase as the standard New Keynesian model would suggest. This finding is consistent with many empirical studies often reaching a similar finding when identifying monetary policy shocks in structural VARs.

As discussed above, our model can generate a price puzzle because of the interaction of roundabout production with the working capital channel applied to all variable factors of production. Working capital makes the interest rate a direct component of marginal cost. A decrease in the interest rate applies downward pressure on marginal cost, which works against the upward pressure resulting from increases in factor prices due to an expanding economy. Roundabout production reduces the sensitivity of marginal cost to fluctuations in factor prices. When combined, these features result in inflation initially declining after a policy shock.

How sensitive are our results to the parameterization of the model? Figure 3 shows impulse responses of inflation and the price level under some alternative parameterization of our baseline model (which includes both roundabout production and working capital applied to all variable inputs). The solid lines show the responses in our baseline parameterization. The dashed line shows responses when we assume that wages are stickier than in our baseline, with $\xi_{w}=0.75$ instead of 0.66. A value of $\xi_{w}$ is consistent with the micro analysis in Barattieri, Basu, and Gottshalk (2014), and is also consistent with estimates from medium scale DSGE models with many shocks (e.g. Justiniano, Primiceri, and Tambalotti, 2010, 2011). With stickier wages, the initial fall in inflation is even greater than in our baseline parameterization, and is strong enough that the price level response does not turn positive for three quarters, and does not significantly rise for several more quarters after that. In other words, our parameterization of the wage stickiness parameter is conservative with respect to the magnitude of the price puzzle our model can generate. The intuition for this effect is straightforward. The stickier are nominal wages, the less real wages increase after a policy shock. This reinforces the effects of working capital and roundabout production in keep marginal cost from increasing, which results in a smaller initial reaction of inflation.

The dashed lines plot impulse responses with a parameterization implying a more elastic response of capital utilization. Our parameterization of $\gamma_{2}=0.05$ (the parameter which governs the squared term in the utilization cost) is a middle ground between Justiniano, Primiceri, and Tambalotti $(2010,2011)$, who estimate this parameter to be about 0.15, and CEE (2005), who fix this parameter at 0.00035 (in particular, their parameterization fixed $\frac{\gamma_{2}}{\gamma_{1}}=0.01$; given the parameterization of $\gamma_{1}$ to be consistent with steady state utilization of unity, this implies $\gamma_{2}=0.00035$ ). The 
dashed lines show responses when we use the lower value of $\gamma_{2}$ consistent with CEE (2005). Like stickier wages, this also has the effect of magnifying the price puzzle the model generates - inflation initially falls by more, and the price level response does not turn positive for four quarters. In contrast to the impact effect, when capital utilization is more elastic inflation and hence the price level actually respond more positively after several quarters than our baseline specification. The household's first order condition for optimal capital utilization requires that $r_{t}^{k}=a^{\prime}\left(Z_{t}\right)=\gamma_{1}+\gamma_{2}\left(u_{t}-1\right)$ (see the Appendix). A lower value of $\gamma_{2}$ has the effect of making the real rental rate, $r_{t}^{k}$, less sensitive to utilization. This has the effect of keeping the real rental rate from rising as much after an expansionary policy shock, which works to keep marginal cost down, and therefore limits the increase in inflation on impact (or in this case, magnifies the decrease in inflation on impact).

\subsection{Cyclical Price Markup}

The basic transmission mechanism by which positive demand shocks raise output in the textbook New Keynesian model is via a countercyclical price markup over marginal cost (see, e.g. Woodford, 2003, 2011). Nekarda and Ramey (2013) have recently challenged the empirical relevance of this transmission mechanism. In particular, they empirically find that the price markup is procyclical unconditionally, as well as procyclical conditional on an expansionary monetary policy shock.

What implications does our model have for the behavior of the price markup? Figure 4 plots the impulse response of the price markup to an expansionary monetary policy shock for several different specifications of our model. The solid line shows the response of the markup in our baseline model. One observes that the markup initially rises and remains positive for about four quarters, after which time it goes slightly negative before returning to trend. In other words, our model generates a procyclical markup conditional on a monetary policy shock, at least for a few quarters. The response of the markup in our model is qualitatively similar to the conditional procyclicality Nekarda and Ramey (2013) estimate (see Figure 4 in their paper). The dashed line shows the response of the markup in a version of the model without working capital or roundabout production (in other words, what might be considered the "textbook" medium scale New Keynesian model). Consonant with the basic intuition from the textbook sticky price New Keynesian model with flexible wages and without capital, the markup is very countercyclical conditional on the expansionary policy shock in this version of the model.

The dotted line in the Figure plots the impulse response of the markup in a version of the model in which there is neither working capital nor roundabout production, but in which prices and wages are fully indexed to lagged inflation. Though full indexation alone is capable of generating hump-shaped inflation dynamics (see Figure 1), it does little to change the dynamic response 
of the markup. The markup is conditionally countercyclical, falling on impact and obeying similar dynamics to the version of the model without indexation. The dashed line with "+" markers plots the response of the markup in a version of the model with limited borrowing (so that the wage bill is fully financed via working capital, but capital and intermediates are not), no roundabout production, and full indexation. This is essentially the version of the model in Christiano, Eichenbaum, and Evans (2005). This version of the model does generate an initial increase in the price markup after an expansionary policy shock, but the increase is smaller than what our model generates and the price markup does not stay positive for as long as in our model.

Table 3 presents some statistics for the cyclicality of the price markup in these different versions of the model. We measure the cyclicality of the markup by the correlation with real GDP, and use three different filtering devices - first differences, log-levels, and HP-filtered log-levels. For point of comparison, we also include the cyclicalities of the markup estimated by Nekarda and Ramey (2013). Some caution is in order when making comparisons between the model and their data, because their cyclicalities are unconditional whereas ours are conditional on a monetary policy shock. Nevertheless, the comparisons are revealing, so we have chosen to include them.

Regardless of filtering method, our baseline model generates a procyclical markup conditional on a monetary policy shock. The correlation between the first log differences of the price markup and output is 0.42 , which is very close the unconditional correlation estimated by Ramey and Nekarda (2013) of 0.50. In log-levels the correlation in the model is smaller but nevertheless still positive at 0.09. When the series are HP-filtered the correlation between the markup and output is 0.16. This is a bit smaller than what Nekarda and Ramey (2013) report, but is qualitatively in-line with their results.

None of the other specifications of the model are capable of generating a robustly procyclical price markup. In line with the impulse responses shown in Figure 4, the versions of the model without a working capital channel and no roundabout production deliver a highly countercyclical price markup. This is true for all three filters and does not depend on whether there is backward indexation or not. The version of the model with limited borrowing (only the wage bill is financed via working capital) and full indexation is essentially equivalent to the model in CEE (2005). This version of the model meets with some limited success when compared to the analysis in Nekarda and Ramey (2013). While this version of the model generates a mild positive correlation between the the first differences of the price markup and output (correlation of 0.11 , far lower than the correlation our model produces), it predicts a countercyclical price markup in either log-levels or HP filtered log-levels (correlations with output of -0.32 and -0.31 , respectively). Not only does our model generate a procyclical price markup conditional on a monetary policy shock, relative to these 
other specifications it also generates the largest output response to a policy shock (see Figure 1). In other words, our model delivers a highly expansionary monetary policy shock without relying on a countercyclical markup.

Just as it is key to generating a hump-shaped response of inflation to a policy shock, the working capital channel is the key mechanism capable of delivering a conditionally procyclical price markup. Our baseline model assumes that all factors must be fully financed via working capital, i.e. $\psi_{\Gamma}=\psi_{K}=\psi_{L}=1$. One might wonder whether or not intermediate values of these parameters are also capable of generating a procyclical markup. In Figure 5 we plot the cyclicality of the price markup (with the three different filtering methods) for values of $\psi$ between 0 and 1 , where we assume that $\psi_{l}=\psi$ for all three factors. When there is no working capital channel at all $(\psi=0)$, the correlation of the markup with output is close to -1 regardless of filter. When focusing on the correlation in first differences, our model generates a positive correlation between the markup and output conditional on a policy shock for values of $\psi \geq 0.25$. The cutoff value of $\psi$ for a procyclical markup is higher when focusing on correlations in log-levels of when looking at HP filtered data. For HP filtered data, $\psi$ must be bigger than about two-thirds to generate a procyclical markup. In levels, the cutoff value of $\psi$ is roughly 0.85 . In other words, while our model relies on at least some working capital channel to generate a procyclical markup conditional on a policy shock, the entirety of factor payments do not have to be financed with working capital for this result to obtain.

\subsection{The Autocorrelation of the First Difference of Inflation}

Our baseline model with roundabout production and working capital for all variable inputs generates a hump-shaped impulse response of inflation to a monetary policy shock. A model without these features but with full backward indexation of prices and wages to lagged inflation can also generate this feature.

A hump-shaped impulse response function implies positive autocorrelation in first differences. The first inner column of Table 4 shows the first order autocorrelation of the first difference of inflation in our base model with only the monetary policy shock. This autocorrelation is positive at 0.29. We also show the first order autocorrelation of the first difference of inflation in a version of the model with no working capital channel and no roundabout production, but where prices and wages are both fully indexed to lagged inflation. This version of the model also produces a positive autocorrelation of the first difference of inflation, although it is substantially higher than in our baseline model (0.73 versus 0.29 in our baseline model).

While the primary focus of this paper is on the conditional responses to a monetary policy shock, it is of interest to explore the implications of our model conditional on other shocks. While 
virtually all empirical papers find that inflation responds sluggishly and in a hump-shaped fashion to a monetary policy shock, this is generally not the case conditional on other shocks. Galí (1999) identifies a neutral productivity shock in a structural VAR using a long run restriction. He finds that inflation falls sharply in the period of a positive productivity shock, and then reverts monotonically back to trend, with no hump-shape. Using growth accounting techniques to construct a "purified" Solow residual, Basu, Fernald, and Kimball (2006) reach a similar conclusion, finding that the price level adjusts downward quickly conditional on a technology shock. Galí (1992) uses a structural VAR to identify four distinct shocks - a "supply" shock, a monetary policy shock, an "IS shock" (or aggregate demand shock), and a money demand shock. While he finds that inflation responds sluggishly and with a hump-shape to a monetary policy shock (he also estimates a mild price puzzle), he estimates that inflation reacts quickly and without a hump-shape to the three other identified shocks.

We augment our model to include both a productivity shock and a preference shock, the latter of which is meant as a stand-in for aggregate demand disturbances other than a monetary policy shock. To include the productivity shock, we augment the production function of a typical intermediate producter, (12), to include a shift term, $A_{t}$ :

$$
X_{t}(j)=\max \left\{A_{t} \Gamma_{t}(j)^{\phi}\left(\widehat{K}_{t}(j)^{\alpha} L_{t}(j)^{1-\alpha}\right)^{1-\phi}-F, 0\right\},
$$

The exogenous variable $A_{t}$ is common across all firms. It obeys a stationary stochastic process with non-stochastic steady state value normalized to unity and an innovation drawn from a normal distribution with standard deviation equal to $s_{A}$ :

$$
A_{t}=A_{t-1}^{\rho_{A}} \exp \left(s_{A} \varepsilon_{t}^{A}\right), \quad 0<\rho_{A}<1, \quad \varepsilon_{t}^{A} \sim N(0,1)
$$

We model the preference shock as a shock to current flow utility:

$$
U_{t}(h)=\nu_{t}\left(\ln \left(C_{t}-b C_{t-1}\right)-\eta \frac{L_{t}(h)^{1+\chi}}{1+\chi}\right)
$$

The exogenous variable $\nu_{t}$ is common across all households. It follows a stationary stochastic process. Positive innovations to $\nu_{t}$ cause the household to value current utility more than future utility, and are therefore isomorphic to a temporary reduction in the discount factor. The process for $\nu_{t}$ is given below. The non-stochastic steady state value is normalized to one and the innovation is drawn from a standard normal distribution with standard deviation $s_{\nu}$ : 


$$
\nu_{t}=\nu_{t}^{\rho_{\nu}} \exp \left(s_{\nu} \varepsilon_{t}^{\nu}\right), \quad 0<\rho_{\nu}<1, \quad \varepsilon_{t}^{\nu} \sim N(0,1)
$$

We parameterize these shock processes as follows. We set $\rho_{A}=0.95$ and $\rho_{\nu}=0.66$. The standard deviations of the innovations are set to $s_{A}=0.0075(1-\phi)$ and $s_{\nu}=0.025 .^{10}$ In our baseline model which also includes the monetary policy shock, this parameterization generates a standard deviation of output growth of 0.0067 , which is close to its value in the data over the last thirty years. The productivity shock explains 47 percent of the unconditional variance of output growth, the preference shock 38 percent, and the monetary policy shock 15 percent.

Figure 6 plots impulse responses of inflation to each of the three shocks. We do so for two model specifications - our baseline specification (solid line), as well as a specification of the model with no working capital, no roundabout production, but full indexation of prices and wages to lagged inflation (dashed line). Both model specifications generate a hump-shaped response of inflation to a monetary policy shock, with our baseline specification generating a mild price puzzle. There are important differences conditional on the other two shocks. Our model does not generate humpshaped responses of inflation to the productivity or preference shocks, whereas the specification with full backward indexation does. The intuition for this result relates back to the manner in which working capital enters the model. Conditional on a monetary shock, the interest rate falls while factor prices rise, which exerts upward pressure on real marginal cost and hence inflation. A fall in the interest rate counteracts the effect of rising factor prices on marginal cost, which mutes the initial response of inflation to the shock. Conditional on non-monetary shocks, the interest rate and marginal cost tend to move in the same direction because of the reaction of the interest rate to inflation in the Taylor rule. A demand shock, for example, raises inflation and hence also the nominal interest rate. The rise in the nominal interest rate works to further increase marginal cost, which tends to make inflation increase by more than it would without a working capital channel. The same mechanism is at work, but in reverse, conditional on a productivity shock. Hence, our model with working capital does not generate hump-shaped inflation dynamics conditional on nonmonetary shocks. The version of the model with backward price and wage indexation, in contrast, induces inflation inertia conditional on all shocks.

The remaining columns of Table 4 show first order autocorrelations of the first difference of inflation conditional on the productivity and preference shocks, as well as the unconditional autocorrelation of the first difference of inflation when all three shocks are included in the model.

\footnotetext{
${ }^{10}$ The reason for the scaling of the productivity shock is because $A_{t}$ effectively enters the aggregate production function twice because of the presence of intermediate goods (which $A_{t}$ impacts). This scaling ensures that the effect of the productivity shock on TFP (output less share-weighted inputs) is invariant to the value of $\phi$.
} 
Consistent with the pattern of impulse responses, in our baseline model there is either a negative (conditional on the productivity shock) or zero (conditional on the preference shock) first order autocorrelation of the first difference of inflation. Unconditionally, our model generates a mildly negative autocorrelation of the first difference of inflation (-0.09). The version of the model without working capital and roundabout production, but with full backward indexation, in contrast, produces significantly positive autocorrelations of the first difference of inflation conditional on both the productivity and preference shocks. Unconditionally, the model with backward indexation produces a first order autocorrelation of the first difference of inflation of 0.49.

In the data, the unconditional first order autocorrelation of the first difference of inflation is negative. We measure inflation in the data as the first difference of the log GDP price deflator. The bottom rows of Table 4 show the first order autocorrelations of the first difference of inflation for different sample periods. This correlation is robustly negative and ranges between -0.3 and -0.4 depending on the sample period. The lack of a positive unconditional autocorrelation of the first difference of inflation in the data is consistent with many of the VAR papers cited above, which routinely find that inflation is not particularly sluggish except conditional on monetary shocks, which account for only a modest fraction of the overall volatility of output and prices. While our model with roundabout production and working capital does not perfectly match the magnitude of the autocorrelation of the first difference of inflation in the data, it correctly predicts the negative sign. The model without these features but with full backward indexation produces a robustly positive autocorrelation of the first difference of inflation and is therefore strongly at odds with the data.

These results potentially shed some light on an apparent tension in the literature. Authors since CEE (2005) have typically included backward indexation as the principal means by which to introduce sluggish, hump-shaped inflation dynamics conditional on monetary policy shocks. But papers which estimate medium scale DSGE models with several shocks typically do not find backward indexation of prices and wages to be strong - examples include Smets and Wouters (2007), who find that indexation parameters for wages and prices to be about 0.5 and 0.2 , respectively; and Justiniano, Primiceri, and Tambalotti (2011), who find the parameters governing price and wage indexation to both be around 0.1 . The fact that these papers typically find backward indexation to be relatively unimportant is unsurprising in light of the facts that the unconditional autocorrelation of the first difference of inflation is negative and that the estimated contribution of monetary policy shocks to the unconditional volatilities of most variables is small. Our model potentially provides a bridge between these disparate findings in the literature in that it can simultaneously generate a sluggish, hump-shaped response of inflation to a monetary policy shock, while at the 
same time generating non-inertial responses of inflation to other shocks and a negative unconditional autocorrelation of the first difference of inflation.

\section{Conclusion}

In this paper we have built a medium-scale DSGE model and studied its implications for the dynamics of inflation, output, and the price markup over marginal cost. In addition to many of the usual ingredients of these models, our model includes a roundabout production structure and assumes a working capital channel wherein firms have to borrow to finance the cost of all factors of production. The model is able to deliver hump-shaped and inertial inflation dynamics to a monetary policy shock, a large and persistent response of output, and a mild price puzzle. It does so with the price markup being procyclical, as recent empirical evidence suggests is the case. While inflation is hump-shaped and inertial conditional on monetary shocks, it is not inertial conditional on other shocks, and the unconditional autocorrelation of the first difference of inflation in our model is negative, as it is in the data.

Many papers include backward-indexation or rule of thumb price setters into New Keynesian models to help account for the sluggish behavior of inflation. These features are theoretically unattractive and imply that prices and wages adjust every quarter, which is strongly at odds with available evidence. Our analysis suggests that these features are not necessary to understand the inertial behavior of inflation. Our model with purely forward-looking price and wage setting does at least well as a model with backward-indexation in accounting for inertial inflation dynamics, and does better along several other dimensions, including the cyclicality of the markup and the unconditional autocorrelation of the first difference of inflation. 


\section{References}

Altig, David, Lawrence Christiano, Martin Eichenbaum, and Jesper Linde. 2011. "Firm-Specific Capital, Nominal Rigidities, and the Business Cycle." Review of Economic Dynamics 14(2):225247.

Barattieri, Alessandro, Susanto Basu, and Peter Gottschalk. 2014. "Some Evidence on the Importance of Sticky Wages." American Economic Journal: Macroeconomics 6(1):70-101.

Barth, Marvin and Valerie Ramey. 2002. "The Cost Channel of Monetary Transmission." In NBER Macroeconomics Annual 2001, edited by Bernanke Ben S and Kenneth Rogoff. Cambridge, MA, The MIT Press, 1999-239.

Basu, Susanto. 1995. "Intermediate Goods and Business Cycles: Implications for Productivity and Welfare." American Economic Review 85(3):512-531.

Basu, Susanto, John Fernald, and Miles Kimball. 2006. "Are Technology Improvements Contractionary?" American Economic Review 96(5):1418-1448.

Basu, Susanto and Miles Kimball. 1997. "Cyclical Productivity with Unobserved Input Variation." NBER Working Paper 5915.

Bergin, Paul and Robert Feenstra. 2000. "Staggered price setting, translog preferences, and endogenous persistence." Journal of Monetary Economics 45:657-680.

Bernanke, Ben and Ilian Mihov. 1998. "Measuring Monetary Policy." The Quarterly Journal of Economics 113 (3):869-902.

Bils, Mark and Peter J. Klenow. 2004. "Some Evidence on the Importance of Sticky Prices." Journal of Political Economy 112(5):947-985.

Calvo, Guillermo A. 1983. "Staggered Prices in a Utility-Maximising Framework." Journal of Monetary Economics 12:383-398.

Carlstrom, Charles T., Timothy S. Fuerst, and Matthias Paustian. 2009. "Monetary Policy Shocks, Choleski Identification, and DNK Models." Journal of Monetary Economics 56(7):1014-1021.

Chowdhury, Ibrahim, Mathias Hoffmann, and Andreas Schabert. 2006. "Inflation Dynamics and the Cost Channel of Monetary Transmission." European Economic Review 50:995-1016.

Christiano, Lawrence J. and Martin Eichenbaum. 1992. "Liquidity Effects and the Monetary Transmission Mechanism." American Economic Review 82:346-353.

Christiano, Lawrence J., Martin Eichenbaum, and Charles L. Evans. 1997. "Sticky Price and Limited Participation Models of Money: A Comparison." European Economic Review 41:12011249 .

. 1999. "Monetary Policy Shocks: What Have We Learned and to What End?" In Handbook of Macroeconomics, edited by John B. Taylor and Michael Woodford. Amsterdam, North-Holland.

. 2005. "Nominal Rigidities and the Dynamic Effects of a Shock to Monetary Policy." Journal of Political Economy 113 (1):1-45. 
Christiano, Lawrence J., Mathias Trabandt, and Karl Walentin. 2011. "DSGE Models for Monetary Policy Analysis." In Handbook of Monetary Economics, edited by Benjamin M. Friedman and Michael Woodford, chap. 7, Volume 3. San Diego CA: Elsevier, 285-367.

Cogley, Timothy and Argia M. Sbordone. 2008. "Trend Inflation, Indexation and Inflation Persistence in the New Keynesian Phillips Curve." American Economic Review 98 (5):2101-2126.

Dotsey, Michael and Robert G. King. 2006. "Pricing, Production, and Persistence." Journal of the European Economic Association 4(5):893-928.

Erceg, Christopher J., Dale W. Henderson, and Andrew T. Levin. 2000. "Optimal Monetary Policy with Staggered Wage and Price Contracts." Journal of Monetary Economics 46:281-313.

Fuerst, Timothy. 1992. "Liquidity, Loanable Funds, and Real Activity." Journal of Monetary Economics 29(1):3-24.

Fuhrer, Jeffrey and G. Moore. 1995. "Inflation Persistence." Quarterly Journal of Economics 110:127-159.

Galí, Jordi. 1992. "How Well Does the IS-LM Model Fit Postwar U.S. Data?" The Quarterly Journal of Economics 107:709-738.

- 1999. "Technology, Employment, and the Business Cycle: Do Technology Shocks Explain Aggregate Fluctuations?" American Economic Review 89(1):249-271.

Griffin, Peter. 1992. "The Impact of Affirmative Action on Labor: a Test of Some Implications of the Le Chatelier Principle." Review of Economics and Statistics 74:251-260.

Huang, Kevin X.D. and Zheng Liu. 2002. "Staggered Contracts and Business Cycle Persistence." Journal of Monetary Economics 49:405-433.

Huang, Kevin X.D., Zheng Liu, and Louis Phaneuf. 2004. "Why Does the Cyclical Behavior of Real Wages Change Over Time?" American Economic Review 94(4):836-856.

Justiniano, Alejandro and Giorgio Primiceri. 2008. "The Time Varying Volatility of Macroeconomic Fluctuations." American Economic Review 98(3):604-641.

Justiniano, Alejandro, Giorgio Primiceri, and Andrea Tambalotti. 2010. "Investment Shocks and Business Cycles." Journal of Monetary Economics 57(2):132-145.

. 2011. "Investment Shocks and the Relative Price of Investment." Review of Economic Dynamics 14(1):101-121.

Nakamura, Emi and Jon Steinsson. 2008. "Five Facts About Prices: A Reevaluation of Menu Cost Models." Quarterly Journal of Economics 123 (4):1415-1464.

—. 2010. "Monetary Non-Neutrality in a Multi-Sector Menu Cost Model." Quarterly Journal of Economics 125 (3):961-1013.

Nekarda, Christopher and Valerie Ramey. 2013. "The Cyclical Behavior of the Price-Cost Markup." NBER Working Paper No. 19099.

Nelson, Edward. 1998. "Sluggish Inflation and Optimizing Models of the Business Cycle." Journal of Monetary Economics 42:303-322. 
Normandin, Michel and Louis Phaneuf. 2004. "Monetary Policy Shocks: Testing Identification Conditions Under Time-Varying Conditional Volatility." Journal of Monetary Economics $51: 1217-1243$.

Pivetta, Frederic and Ricardo Reis. 2007. "The Persistence of Inflation in the United States." Journal of Economic Dynamics and Control 31 (4):1326-1358.

Ravenna, Federico and Carl Walsh. 2006. "Optimal Monetary Policy with the Cost Channel." Journal of Monetary Economics 53:199-216.

Romer, Christina and David Romer. 2004. "A New Measure of Monetary Shocks: Derivation and implications." American Economic Review 94:1055-1084.

Rotemberg, Julio J. and Michael Woodford. 1993. "Dynamic General Equilibrium Models with Imperfectly Competitive Product Markets." NBER Working Paper no. 4502.

- 1997. "An Optimization-Based Econometric Framework for the Evaluation of Monetary Policy." In NBER Macroeconomics Annual 1997, edited by Julio J. Rotemberg and B. S. Bernanke. Cambridge, MA, The MIT Press, 297-346.

Sims, Christopher A. 1992. "Interpreting the Macroeconomic Time Series Facts: The Effects of Monetary Policy." European Economic Review 36(5):975-1000.

Smets, Frank and Raf Wouters. 2007. "Shocks and Frictions in US Business Cycles: A Bayesian DSGE Approach." American Economic Review 97 (3):586-606.

Woodford, Michael. 2003. Interest and Prices: Foundations of a Theory of Monetary Policy. Princeton: Princeton University Press.

. 2011. "Simple Analytics of the Government Expenditure Multiplier." American Economic Journal: Macroeconomics 3(1):1-35. 
Figure 1: Output, Inflation, and Price Level Responses
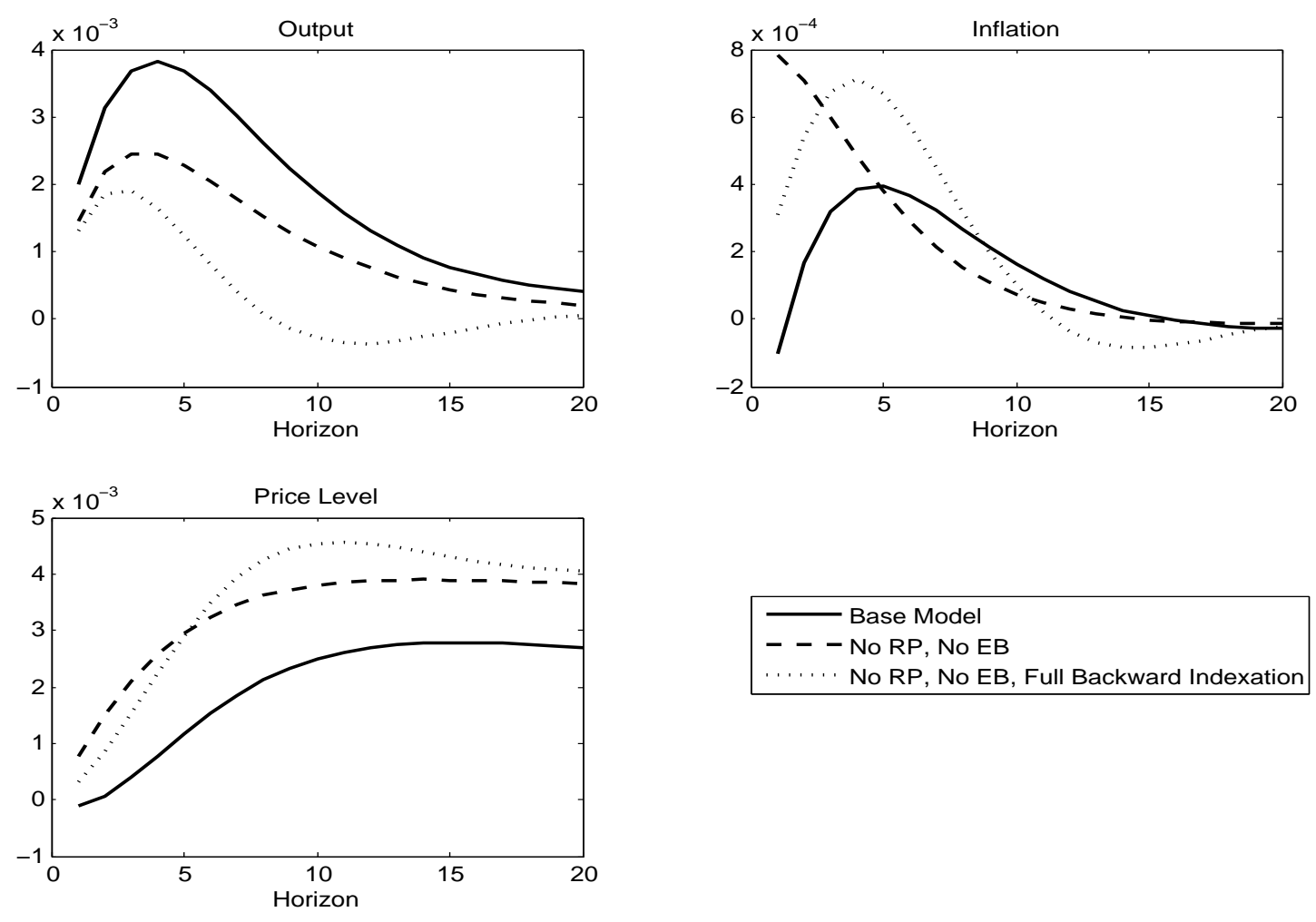

Note: this figure plots the impulse responses of output, inflation, and the price level to a monetary policy shock. The solid lines show the responses in the baseline calibrated model. The dashed lines show responses when there is no roundabout production and no extended borrowing ("No RP, No EB"). The dotted lines show responses when there is no roundabout production and no extended borrowing, but prices and wages are fully indexed to the lagged inflation rate ("No RP, No EB, Full Backward Indexation"). 
Figure 2: Output and Inflation Responses: Roundabout Production and Working Capital
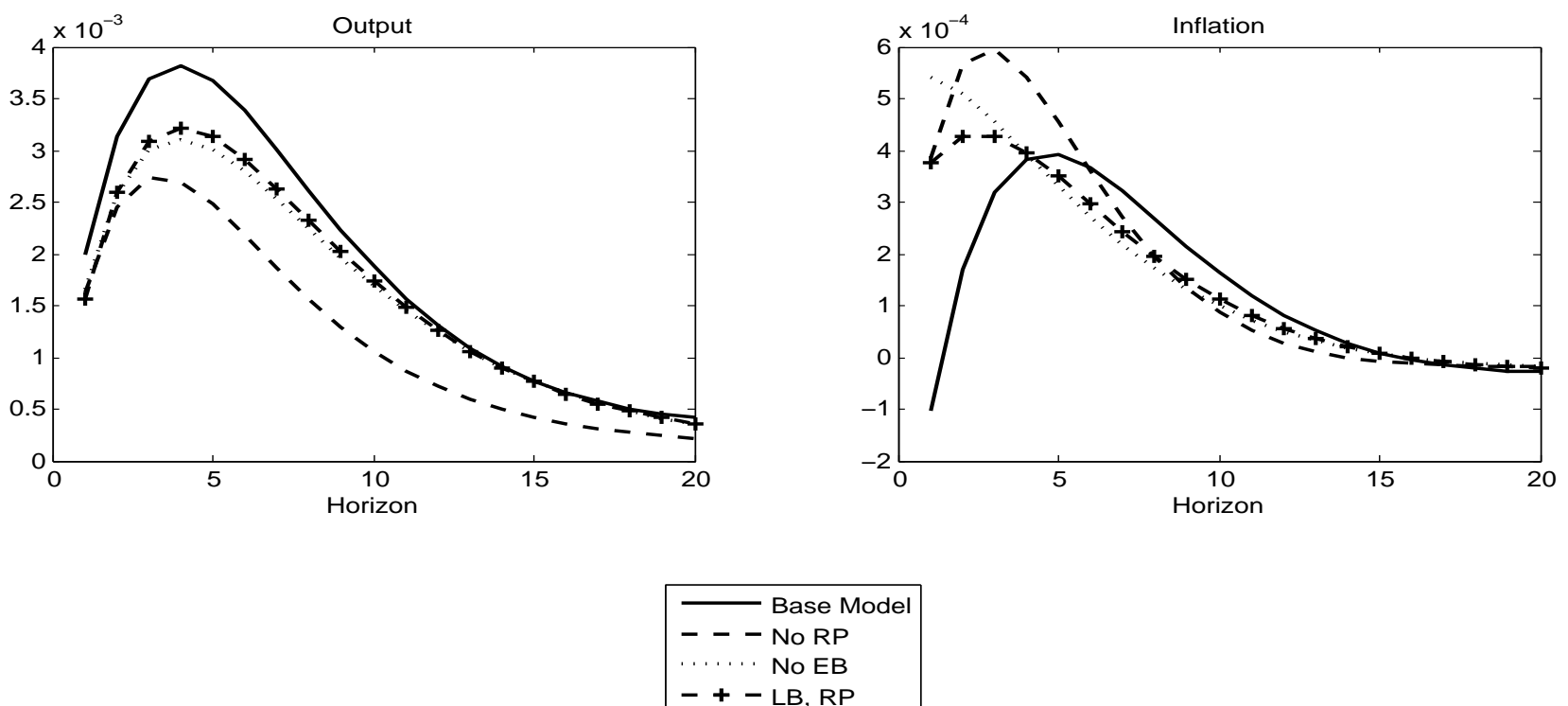

Note: this figure plots impulse responses of inflation to three different shocks in the model - the monetary policy shock, a productivity shock, and a preference shock. We do so under two cases: our base model (solid line), and a version of the model with no roundabout production and no extended borrowing, but where prices and wages are fully indexed to the lagged inflation rate ("No RP, No EB, Full Backward Indexation"). The processes for the productivity and preference shock are described in the text. 
Figure 3: Inflation and Price Level Responses: Price Puzzle
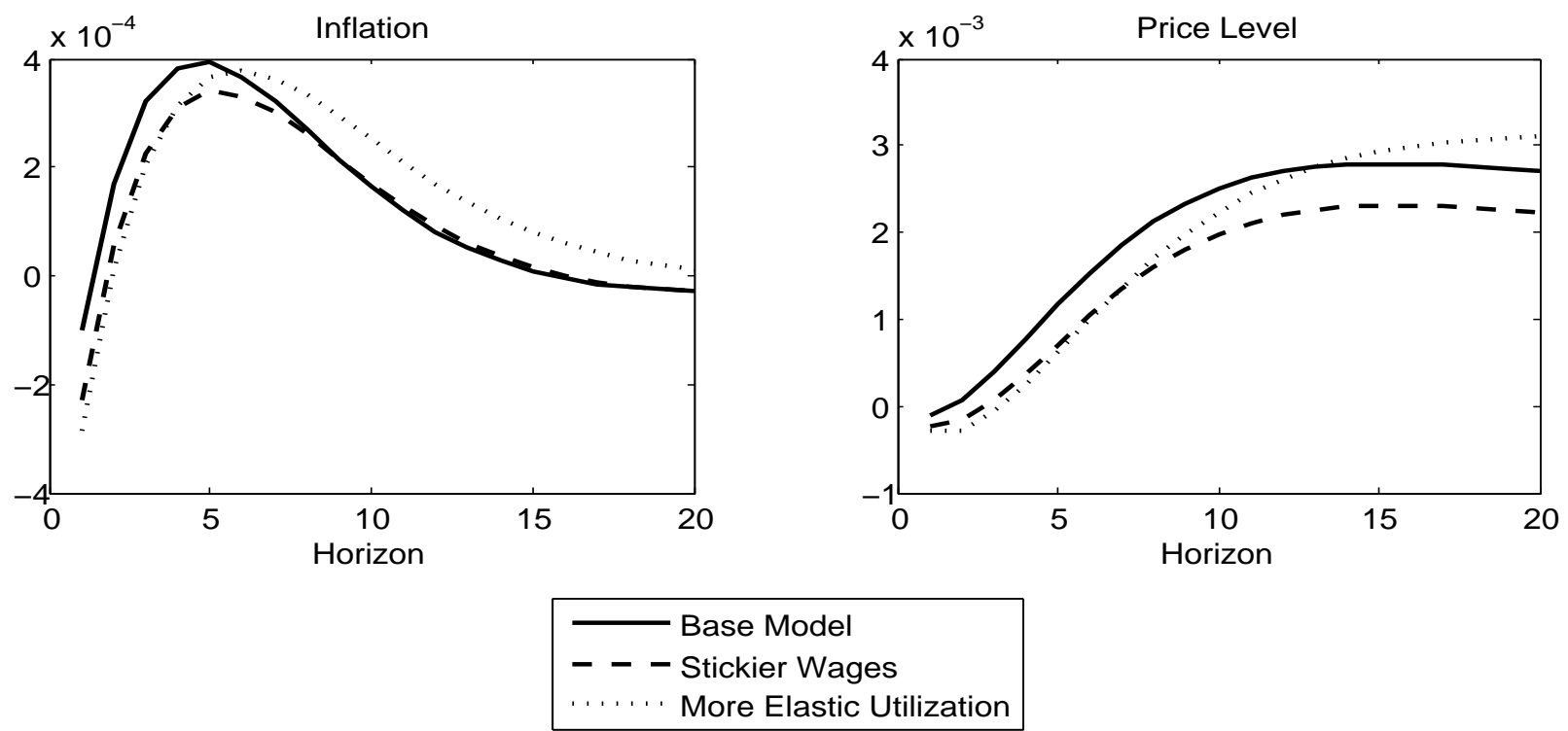

Note: this figure plots impulse responses of inflation and the price level to a monetary policy shock for four different parameterizations of the baseline model. The solid lines depict the responses under a baseline parameterization. The dashed line considers the case where wages are stickier, with $\xi_{w}=0.75$ instead of 0.66 . The dotted line considers the case in which capital utilization is more elastic. For this specification we assume that $\frac{\gamma_{2}}{\gamma_{1}}=0.01$, as in Christiano, Eichenbaum, and Evans (2005). annualized. 


\section{Figure 4: Impulse Response of Price Markup}

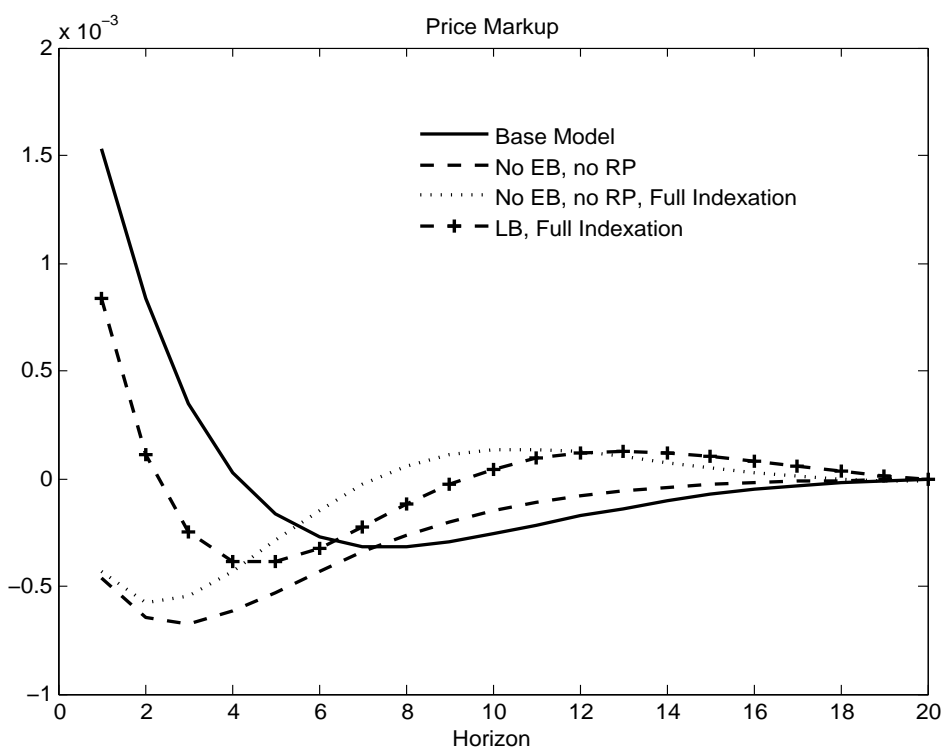

Note: this figure plots impulse responses of the price markup to a monetary policy shock. The solid line depicts responses in our base model. The dashed lines show response in the model without working capital and without roundabout production ("No EB, no RP"). The dotted lines show the response when there is no working capital and no roundabout production, but full backward indexation of prices and wages to laggged inflation ("No EB, no RP, Full Indexation"). The dashed line with "+" markers shows the responses when there is limited borrowing (so that only the wage bill must be financed), no roundabout production, and full backward indexation ("LB, Full Indexation"). 
Figure 5: Extent of Working Capital and the Cyclicality of the Markup

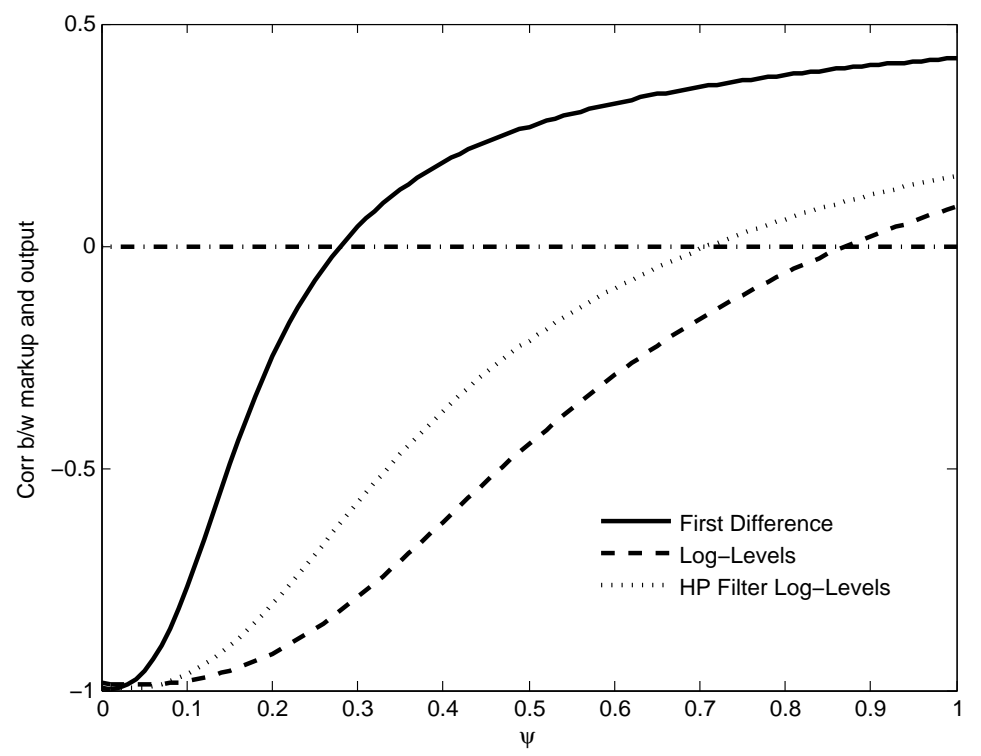

Note: this figure plots the correlation between the price markup and output (in first log-differences (solid line), log-levels (dashed line), and HP filtered log-levels (dotted line)) as a function of the value of $\psi$, where we assume that $\psi_{\Gamma}=\psi_{K}=\psi_{L}=\psi$. In other words, the parameter $\psi$ measures the fraction of factor payments that have to be financed with working capital, assuming that this fraction is the same for all three factors of production. The dashed-dotted line is drawn at zero to facilitate determining the threshold value of $\psi$ capable of delivering a procyclical markup. 
Figure 6: Inflation Response to Other Shocks
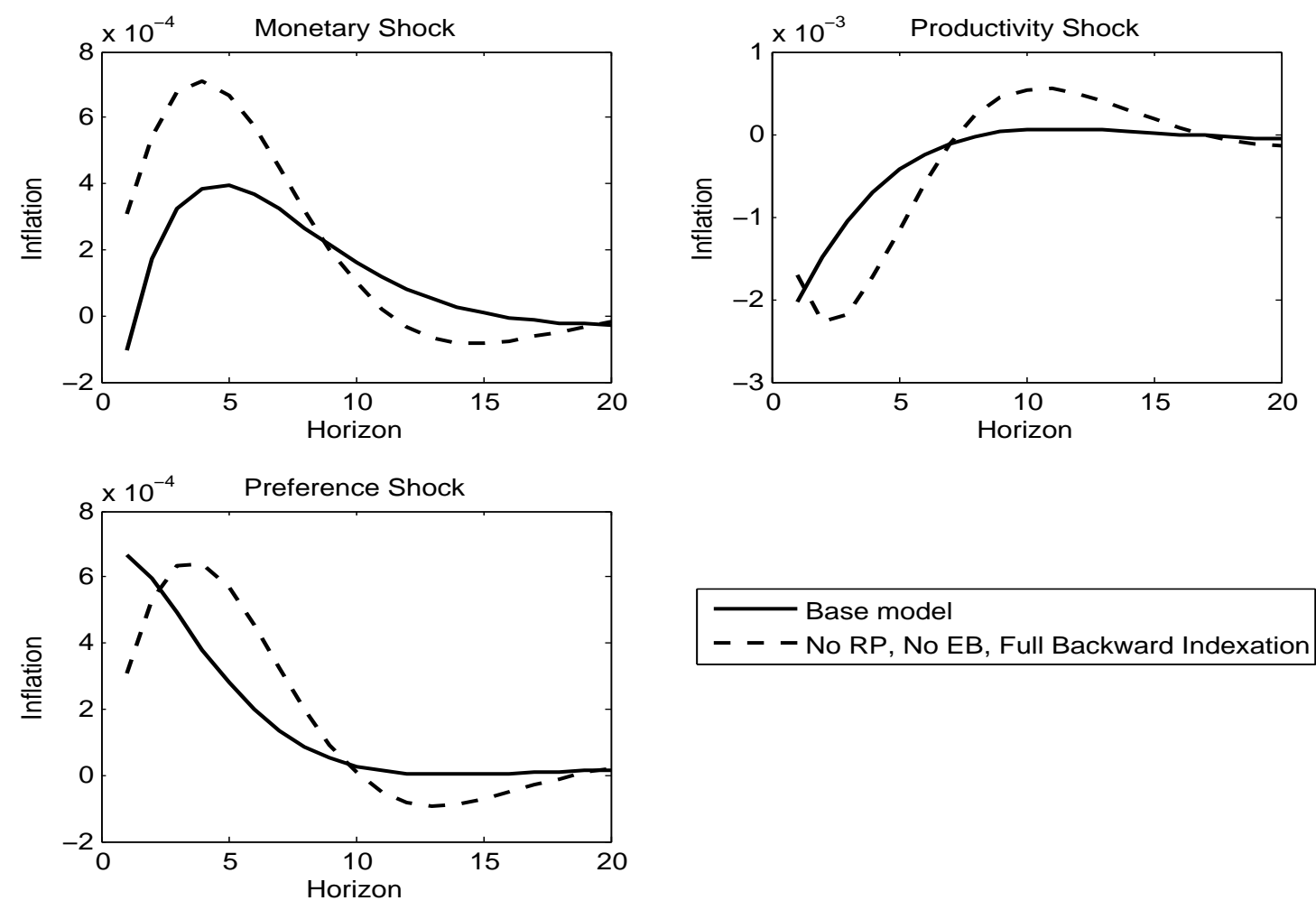

Note: this figure plots impulse responses of inflation to three different shocks in the model - the monetary policy shock, a productivity shock, and a preference shock. We do so under two cases: our base model (solid line), and a version of the model with no roundabout production and no extended borrowing, but where prices and wages are fully indexed to the lagged inflation rate ("No RP, No EB, Full Backward Indexation"). The processes for the productivity and preference shock are described in the text. 
Table 1: Parameter Values

\begin{tabular}{lll}
\hline \hline Parameter & Value & Description \\
\hline$\beta$ & 0.99 & Discount factor \\
$b$ & 0.8 & Internal habit formation \\
$\eta$ & 6 & Labor disutility \\
$\chi$ & 1 & Frisch elasticity \\
$\kappa$ & 5 & Investment adjustment cost \\
$\delta$ & 0.025 & Depreciation rate \\
$\gamma_{1}$ & $Z^{*}=1$ & Utilization adjustment cost linear term \\
$\gamma_{2}$ & 0.05 & Utilization adjustment cost squared term \\
$\xi_{p}$ & 0.66 & Calvo price \\
$\xi_{w}$ & 0.66 & Calvo wage \\
$\zeta_{p}$ & 0 & Price indexation \\
$\zeta_{w}$ & 0 & Wage indexation \\
$\theta$ & 6 & Elasticity of substitution: goods \\
$\sigma$ & 6 & Elasticity of substitution: labor \\
$\phi$ & 0.624 & Intermediate share \\
$\alpha$ & $1 / 3$ & Capital share \\
$F$ & $\Pi^{*}=0$ & Fixed cost \\
$\psi_{L}$ & 1 & Fraction of labor financed \\
$\psi_{K}$ & 1 & Fraction of capital financed \\
$\psi_{\Gamma}$ & 1 & Fraction of intermediates financed \\
$\rho_{i}$ & 0.8 & Taylor rule smoothing \\
$\alpha_{\pi}$ & 1.5 & Taylor rule inflation \\
$\alpha_{y}$ & 0.2 & Taylor rule output growth \\
$\pi^{*}$ & 0 & Trend inflation \\
$s_{i}$ & 0.002 & SD Taylor rule shock \\
\hline \hline
\end{tabular}

Note: this table shows the values of the parameters used in quantitative analysis of the model. A description of each parameter is provided in the right column. The parameter on the linear term in the utilization adjustment cost function, $\gamma_{1}$, is chosen to be consistent with a steady state normalization of utilization to 1 . Given other parameters this implies a value $\gamma_{1}=0.0351$. The fixed cost of production, $F$, is chosen so that profits equal zero in the non-stochastic steady state. Given other parameters, this implies a value of $F=0.0191$.

Table 2: Output and Inflation Dynamics

\begin{tabular}{llccccc}
\hline \hline & & \multicolumn{5}{c}{ Inflation autocorrelation } \\
& Output half-life & 1 & 2 & 3 & 4 & 5 \\
\hline Base model & 14 & 0.9248 & 0.8054 & 0.6682 & 0.5307 & 0.4032 \\
No EB, no RP & 12 & 0.8331 & 0.6659 & 0.5153 & 0.3877 & 0.2842 \\
No EB, no RP, full indexation & 6 & 0.9507 & 0.8293 & 0.6662 & 0.4893 & 0.3203 \\
\hline \hline
\end{tabular}

Note: this table shows some statistics from different versions of the model. The column labeled "Output half-life" shows the half-life of output in response to a monetary policy shock, which we define as the number of quarters (rounded to the nearest integer) after which the impulse response of output is one-half its impact response. The remaining columns show autocorrelations of inflation at different lags. "Base model" refers to our baseline model. "No EB, No RP" refers to a specification of the model in which there is no working capital channel and no roundabout production; "No RP, No EB, Full Indexation" is similar but assumes full backward indexation of prices and wages to lagged inflation. 
Table 3: Cyclicality of Price Markup

\begin{tabular}{lrrr}
\hline \hline & First Differences & Log-Levels & HP Filtered Log-Levels \\
\hline Base Model & 0.4226 & 0.0877 & 0.1589 \\
No EB, No RP & -0.9793 & -0.9653 & -0.9700 \\
No EB, No RP, Full Indexation & -0.9883 & -0.9815 & -0.9835 \\
LB, No RP, Full Indexation & 0.1068 & -0.3170 & -0.3109 \\
Nekarda and Ramey (2013) & 0.495 & $\mathrm{n} / \mathrm{a}$ & 0.3250 \\
\hline \hline
\end{tabular}

Note: this table shows statistics for the cyclicality of the price markup (correlation of the markup with a output) in different versions of the model for different filtering methods. The column labeled "First Differences" looks at the correlations between the first differences of the price markup and output. The column labeled "Log-Levels" shows correlations between the log-levels of the price markup and output (since our model abstracts from trend growth, one can think of this column as corresponding to linearly detrended log series). The final column column presents correlations between the HP filtered price markup and output (smoothing parameter 1600). The row "Base Model" uses our baseline model. The row labeled "No EB, No RP" omits a working capital channel and has no roundabout production; the row labeled "No EB, no RP, Full Indexation" is similar but assumes full backward indexation of both prices and wages. The row labeled "LB, No RP, Full Indexation" is essentially the Christiano, Eichenbaum, and Evans (2005) specification: it features limited borrowing (the wage bill must be financed, but not capital or intermediate goods), there is no roundabout production, and there is full backward indexation of prices and wages. The final row shows numbers from the data presented by Ramey and Nekarda (2013): these are correlations of the markup with real GDP assuming that the production function is Cobb-Douglas and the data are from the private business sector (row 1 of their Table 1).

Table 4: Autocorrelation of First Difference of Inflation

\begin{tabular}{lrrrr}
\hline \hline & Monetary & Productivity & Preference & Unconditional \\
\hline Base model & 0.2944 & -0.1055 & 0.0016 & -0.0858 \\
No EB, No RP, full indexation & 0.7311 & 0.4662 & 0.6988 & 0.4900 \\
Data, 1960-2015 & & & & -0.2940 \\
Data, 1960-1983 & & & & -0.2367 \\
Data, 1984-2015 & & & -0.3926 \\
\hline \hline
\end{tabular}

Note: this table presents first order autocorrelations of the first difference of inflation in different versions of the model as well as in the data. We do so conditional on the three different shocks described in Subsection 3.4, as well as unconditionally when all three shocks are included in the model. The parameterization of the additional shock processes is as described in the text. "Base Model" refers to our baseline model. "No EB, No RP, Full Indexation" omits working capital and roundabout production from the model, but assumes full backward indexation of both prices and wages to lagged inflation. The rows labeled "Data" compute the first order autocorrelation of the first difference of inflation in various different subsamples. We measure inflation as the log first difference of the GDP Implicit Price Deflator. 


\section{A Full Set of Equilibrium Conditions}

This appendix lists the full set of equilibrium conditions:

$$
\begin{aligned}
& \lambda_{t}^{r}=\frac{1}{C_{t}-b C_{t-1}}-E_{t} \frac{\beta b}{C_{t+1}-b C_{t}} \\
& r_{t}^{k}=\gamma_{1}+\gamma_{2}\left(Z_{t}-1\right) \\
& \lambda_{t}^{r}=\mu_{t}\left(1-\frac{k}{2}\left(\frac{I_{t}}{I_{t-1}}-1\right)^{2}-\kappa\left(\frac{I_{t}}{I_{t-1}}-1\right) \frac{I_{t}}{I_{t-1}}\right)+\beta E_{t} \mu_{t+1} \kappa\left(\frac{I_{t+1}}{I_{t}}-1\right)\left(\frac{I_{t+1}}{I_{t}}\right)^{2} \\
& \mu_{t}=\beta E_{t} \lambda_{t+1}^{r}\left(r_{t+1}^{k} Z_{t+1}-\left(\gamma_{1}\left(Z_{t+1}-1\right)+\frac{\gamma_{2}}{2}\left(Z_{t+1}-1\right)^{2}\right)\right)+\beta(1-\delta) E_{t} \mu_{t+1} \\
& \lambda_{t}^{r}=\beta E_{t}\left(1+i_{t}\right) \pi_{t+1}^{-1} \lambda_{t+1}^{r} \\
& w_{t}^{*}=\frac{\sigma}{\sigma-1} \frac{f_{1, t}}{f_{2, t}} \\
& f_{1, t}=\eta\left(\frac{w_{t}}{w_{t}^{*}}\right)^{\sigma(1+\chi)} L_{t}^{1+\chi}+\beta \xi_{w} \pi_{t}^{-\zeta_{w} \sigma(1+\chi)} E_{t}\left(\pi_{t+1}\right)^{\sigma(1+\chi)}\left(\frac{w_{t+1}^{*}}{w_{t}^{*}}\right)^{\sigma(1+\chi)} f_{1, t+1} \\
& f_{2, t}=\lambda_{t}^{r}\left(\frac{w_{t}}{w_{t}^{*}}\right)^{\sigma} L_{t}+\beta \xi_{w} \pi_{t}^{\zeta_{w}(1-\sigma)} E_{t}\left(\pi_{t+1}\right)^{\sigma-1}\left(\frac{w_{t+1}^{*}}{w_{t}^{*}}\right)^{\sigma} f_{2, t+1} \\
& \widehat{K}_{t}=\alpha(1-\phi) \frac{m c_{t}}{r_{t}^{k}}\left(s_{t} X_{t}+F\right) \\
& L_{t}=(1-\alpha)(1-\phi) \frac{m c_{t}}{\left(1+i_{t}\right) w_{t}}\left(s_{t} X_{t}+F\right) \\
& \Gamma_{t}=\phi m c_{t}\left(s_{t} X_{t}+F\right) \\
& p_{t}^{*}=\frac{\theta}{\theta-1} \frac{x_{t}^{1}}{x_{t}^{2}} \\
& x_{t}^{1}=\lambda_{t}^{r} m c_{t} X_{t}+\xi_{p} \beta \pi_{t}^{-\zeta_{p} \theta} \pi_{t+1}^{\theta} x_{t+1}^{1} \\
& x_{t}^{2}=\lambda_{t}^{r} X_{t}+\xi_{p} \beta \pi_{t}^{\zeta_{p}(1-\theta)} \pi_{t+1}^{\theta-1} x_{t+1}^{2} \\
& 1=\xi_{p} \pi_{t}^{\theta-1} \pi_{t-1}^{\zeta_{p}(1-\theta)}+\left(1-\xi_{p}\right)\left(p_{t}^{*}\right)^{1-\theta} \\
& w_{t}^{1-\sigma}=\xi_{w}\left(\frac{w_{t-1} \pi_{t-1}^{\zeta_{w}}}{\pi_{t}}\right)^{1-\sigma}+\left(1-\xi_{w}\right)\left(w_{t}^{*}\right)^{1-\sigma} \\
& Y_{t}=X_{t}-\Gamma_{t} \\
& s_{t} X_{t}=\Gamma_{t}^{\phi} \widehat{K}_{t}^{\alpha(1-\phi)} L_{t}^{(1-\alpha)(1-\phi)}-F \\
& Y_{t}=C_{t}+I_{t}+\left(\gamma_{1}\left(Z_{t}-1\right)+\frac{\gamma_{2}}{2}\left(Z_{t}-1\right)^{2}\right) K_{t} \\
& K_{t+1}=\left(1-\frac{\kappa}{2}\left(\frac{I_{t}}{I_{t-1}}-1\right)^{2}\right) I_{t}+(1-\delta) K_{t}
\end{aligned}
$$




$$
\begin{gathered}
\frac{1+i_{t}}{1+i}=\left(\frac{1+i_{t-1}}{1+i}\right)^{\rho_{i}}\left[\left(\frac{\pi_{t}}{\pi}\right)^{\alpha_{\pi}}\left(\frac{Y_{t}}{Y_{t-1}}\right)^{\alpha_{y}}\right]^{1-\rho_{i}} \varepsilon_{t}^{i} \\
\widehat{K}_{t}=Z_{t} K_{t} \\
s_{t}=\left(1-\xi_{p}\right) p_{t}^{*-\theta}+\xi_{p} \pi_{t-1}^{-\zeta_{p} \theta} \pi_{t}^{\theta} s_{t-1}
\end{gathered}
$$

Equation (A1) defines the real multiplier on the flow budget constraint. (A2) is the optimality condition for capital utilization. (A3) and (A3) are the optimality conditions for the household choice of investment and next period's stock of capital, respectively. The Euler equation for bonds is given by (A5). (A6)-(A8) describe optimal wage setting for households given the opportunity to adjust their wages. Optimal factor demands are given by equations (A9)-(A11). Optimal price setting for firms given the opportunity to change their price is described by equations (A12)-(A14). The evolutions of aggregate inflation and the aggregate real wage index are given by (A15) and (A16), respectively. Net output is gross output minus intermediates, as given by (A17). The aggregate production function is (A18). The aggregate resource constraint is (A19), and the law of motion for physical capital is given by (A20). The Taylor rule for monetary policy is (A21). Capital services are defined as the product of utilization and physical capital, as in (A22). The law of motion for price dispersion is (A23). 